\title{
Subsidies on Low Skilled's Social Security Contributions: the Case of Belgium*
}

\author{
John Dagsvik (Statistics Norway and the Frisch Centre for Economic Research) \\ Kristian Orsini (KU Leuven and IZA) \\ Zhiyang Jia (Statistics Norway and the Frisch Centre for Economic Research)
}

\author{
Working Paper
}

This Draft: June 6, 2008

\begin{abstract}
Belgium is characterised by a comparatively high tax wedge. Starting from the end of the 90's there has been a growing concern over the effect of high labour costs on the employment of low skilled workers. One of the most innovative measures implemented by the federal government is the targeted reduction on social security contributions for low skilled workers: the Workbonus. The subsidy has increased steadily over the period 2000-2006. At the same time the eligibility to the benefit was considerably extended. The innovative feature of the tax credit is that - differently from other measure existing in OECD countries - eligibility is based on full-time equivalent earnings. The instrument therefore distinguishes between low skill and low effort and avoids the disincentive effect on labour supply at the intensive margin that is typically found in traditional measures means-tested on disposable income or earnings. This paper assesses the effects of the Workbonus on labour supply using different econometric frameworks. In particular, we compare estimates based on a traditional labour supply model, with results based on a modeling framework which accounts for heterogeneity in individuals' job opportunities. Results show that accounting for demand side constraints leads to significantly lower estimates of labour supply effects. Nevertheless, the measure has a positive impact on labour supply and comparatively low cost per additional job created.
\end{abstract}

Keywords: Tax-benefit Systems - Microsimulation - Labour Supply - Structural Modeling.

JEL Classification: D31, H21, H23, H24, H31, J22.

*The authors thank Guy van Camp for the kind assistance with the data. The authors are indebted with André Decoster, Guy van Camp for useful remarks. The usual disclaimer applies. The development of the MIMOSIS model was supported by Federal Science Policy within the framework of the AGORA programme, on the request of the F.P.S. Social Security, who is responsible for the management and the maintenance of the MIMOSIS model. The model is based on administrative data from the Datawarehouse Labour market and Social protection, managed and maintained by the Crossroads Bank for Social Security. Financial support from the FWO (Fonds voor Wetenschappelijk Onderzoek - Vlaanderen) is gratefully acknowledged. Correspondence: Kristian Orsini, CES-KUL, Naamsestraat 69, Leuven, 3000 Belgium. Email: kristian.orsini@econ.kuleuven.be 


\section{Introduction}

In the framework of the Lisbon-strategy, Belgium is faced with the challenge of increasing its employment rates. According to EUROSTAT, the overall employment rate amounts to $60.3 \%$ (2006), compared to $63.5 \%$ for the entire European Union (EU-27). Particularly striking in the case of Belgium is the gap between the employment rates of the less educated and the medium and highly educated population. The employment rate of the low skilled (ISCED 0-2) population aged between 25 and 64 years is only $39.4 \%$ in 2006, as opposed to an average of $46.9 \%$ for EU-27, and of $50.6 \%$ for EU-15. In contrast, the employment rate of the high skilled population is $82.3 \%$ in Belgium i.e. in line with the EU-15 average of $82.9 \%$. For the medium skilled population the gap with respect to the EU-15 is in the order of 6 percentage points.

While globalisation and skill biased technological change are often invoked to explain the weak employment rates amongst the less skilled population (Moore and Ranjan, 2005), the wide range of cross national variation in the employment rates of low skilled workers suggests that institutional characteristics of local labour markets have a significant impact on the performance of employment amongst the less skilled. In particular the level of regulation of the labour market is often supposed to have a more adverse effect on this group. Similarly, high labour costs tend to have a stronger impact on the employability of low skilled labour, since the labour demand for low skilled workers is more elastic than the labour demand for high skilled labour.

From a labour supply perspective, the tax and benefit system has an important impact on the financial incentives faced by households to enter the labour market. It is often argued that the high level of taxation on labour income coupled with generous income support out of employment is one of the main causes of persistent lower employment levels amongst the low skilled population. While income support for the unemployed is not particularly high in Belgium, the tax burden tends to be comparatively high. According to EUROSTAT, the tax burden on low earnings was in the order of $49.2 \%$ in Belgium, i.e. the highest of all EU-27. In the same year the EU-27 and EU-15 averages were of $39.7 \%{ }^{1}$

The European countries characterised by high taxes - high benefits systems have implemented several instruments (i.e. generalised reductions of personal income tax, tax credits on low earnings, subsidies on social security contributions and/or in-work benefits) aiming at improving the financial incentives to take up work amongst the low skilled population, while maintaining high levels of social protection. The potential labour supply effects of these so-called 'Making Work Pay' (MWP) policies are reviewed in Orsini (2006b).

In order to analyse the potential behavioural effects on reforms of the tax and benefit system one needs a structural labour supply model. Unfortunately, there is no general agreement in the research community on which approach is the best to this end. An important generalisation of the conventional textbook model to accommodate nonconvex budget sets was made by Hausman and others, see for example Hausman and Ruud (1984) and the references therein. However, the so-called Hausman approach has turned out to be impractical as regards complicated nonlinear

\footnotetext{
${ }^{1}$ Low earnings correspond to $2 / 3$ of average earnings.
} 
budgets constraints, see Bloemen and Kapteyn (2008) for a discussion on this topic.

van Soest (1995) proposed a discrete choice approach to labor supply modeling. The advantage with this approach is that it is much more practical than the conventional continuous choice approach in the presence of complicated budget constraints. Neither the Hausman model nor the conventional discrete choice model can, however, easily deal with rationing of jobs and quantity restrictions on hours of work. Typically, figures on distributions of hours of work show substantial peaks at full-time and possibly part-time hours of work, which is reasonable to interpret as stemming from restrictions on hours of work. As a result, the conventional and the discrete choice models are unable to account for observed peaks at full-time and part-time hours of work found in most countries. An ad hoc adjustment consists in introducing in the standard model alternative specific disutilities, which supposedly capture the higher search costs related to job opportunities with standard and non-standard hours requirements.

The alternative modeling approach examined in this paper is based on the model developed by Dagsvik and Strøm (2006) and Dagsvik and Jia (2008). Similarly to the models of van Soest (1995), this approach is also developed within a discrete choice framework. Theoretically, however, it differs in that labour supply behavior is viewed as an outcome of agents' choices from a set of feasible jobs, each of which is characterised by offered hours of work and nonpecuniary (qualitative) attributes. Moreover the set of available job opportunities varies amongst the agents - allowing for a rationing effect that is neglected in the standard modeling.

The aim of this paper is twofold: on the one hand it discusses alternative approaches for modeling labour supply for the purpose of policy evaluations, and on the other hand it provides an assessment of the impact of the Workbonus - an innovative 'MWP' instrument recently introduced in Belgium, that could be of great interest for continental European countries with labour markets and institutional setting similar to the Belgian one.

The structure of the paper is as follows: section 2 describes the peculiarities of the Belgian Workbonus by comparing it to other 'MWP' policies, section 3 presents the data and the microsimulation model, section 4 describes in detail the labour supply models used and section 5 discusses the estimates, section 6 analyses the impact of the Workbonus and section 7 concludes.

\section{2 'Making Work Pay' policies and the Belgian Workbonus}

Instruments to increase the financial incentives of the less skilled population to take up work have been increasingly popular in continental Europe in the past decade. Germany, France, the Netherlands and Belgium have all introduced measures to boost the income of low skilled workers (Orsini, 2006b).

These supply side policies follow an orientation that has since long characterised the AngloSaxon countries. An overall reduction of the tax burden was at the heart of policy reforms that took place in the UK and later in the US starting from the end of the 70s when the Thatcher and the Reagan administrations brought about extensive tax cuts. More important for the low skilled workers were however the Earned Income Tax Credit (EITC) and the Family Credit (FC), 
eventually replaced by the Working Family Tax Credit (WFTC). Both policy instruments were specifically designed to encourage employment amongst the low skilled population, by increasing the revenue of poor households where one or both parents are engaged in paid work.

Despite the relative consensus on the need of such targeted instruments, concerns arise about their optimal design. Policies which are means-tested on household rather than individual income, such as the EITC or the WFTC, are better targeted at households in need, such as lone mothers, but may also discourage second-earners' labour supply and women's in particular. Several studies point at these contrastive effects, using both 'ex-ante' and 'ex-post' methodologies: see Eissa and Liebman (1996), Bingley and Walker (1997), Eissa and Hoynes (2004), Duncan and Giles (1996) and Blundell et al. (2000). Bargain and Orsini (2006) have simulated the WFTC for Germany and France and find that the measure would have an overall negative impact on labour supply due to the strong disincentive on the labour supply of females in couples.

Individualised schemes such as the Dutch 'Arbeidskorting' or the former Belgian tax credit on low earnings (Crédit d'impôt pour les bas revenus d'activité profesionnelle - Belastingkrediet voor lage inkomsten) have less ambiguous effects on the labour supply of secondary earners, but they face difficulties in targeting the most needy households. Moreover, measures which are phasedout as earnings increase, still have a negative impact on labour supply at the intensive margin (Orsini, 2006a).

After decades of demand side policies, policy makers in Belgium have recently implemented supply policies aiming at reducing unemployment and inactivity through decreasing the tax burden on labour income - especially for the low skilled. Indeed, Belgium is the EU country where the taxation on the low earnings is the highest. As it is the case in most Bismarckian welfare states, the high tax burden on low earnings is often driven by the flat-rate contribution rates of the compulsory insurance system.

A targeted reduction on the social security contributions (SSC) of low skilled workers has been in place since 2000. The subsidy was progressively extended over the years. Following the 2004 expansion, the subsidy became known as the Workbonus (Bonus à l'emploi - Werkbonus). In 2006, the budgetary cost increased to over 650 million EUR/year (i.e. slightly over .2\% of GDP). Table 1 shows the level of the benefit in 2000, 2001 and 2006, while figure 1 gives a graphical representation of the progressive extension of the subsidy. As shown in the picture, not only has the level of the subsidy increased significantly over time, but eligibility has been progressively extended to medium-low earnings. In the 2000 system, according to the National Office for Social Security, less than 250,000 persons were eligible, as compared to over a million in 2006.

The design of the bonus is fairly simple: individuals with full-time equivalent (FTE) earnings up to a threshold of 1053.55 EUR in 2000 (1125.19 EUR and 1258.88 EUR in 2001 and 2006 respectively) and above a minimum level are eligible to the full amount of the benefit: 64.45 EUR per month (81.8 EUR and 140 EUR per month in 2001 and 2006 respectively). As FTE earnings exceed such threshold, the SSC reduction is tapered away at a rate of 0.40 (0.3806 and 0.1712 in 
2001 and 2006 respectively) until it reaches zero. ${ }^{2}$

One of the peculiarities of the Workbonus is that eligibility and level of the benefit are directly related to the individual's earning potential, rather than the actual earnings. That is, in order to define eligibility, current earnings are transformed into full-time equivalent earnings. Consequently, medium or high skilled workers only working part-time or a marginal amount of hours are not entitled to the benefit. Moreover the amount of the benefit is computed pro-rata with respect to working time, so that workers working part-time at minimum wage only get $50 \%$ of the benefit.

This feature distinguishes the Belgian subsidy from similar measures implemented in the UK, Germany, and the Netherlands. ${ }^{3}$ Screening out workers with low earnings due to low effort (labour supply), the subsidy avoids the well known inconvenient built-in in most income or earning tested instruments, that individuals reduce labour supply at the intensive margin finding compensation in the subsidy.

\section{Data and microsimulation model}

The analysis relies on a sample of administrative data constructed in a two step sampling procedure. First a random sample of 100,000 individuals was sampled from the set of all individuals who, according to the National Register, were alive on January 1st 2002 and known to have their main place of residence in Belgium. Individuals in this random sample could be either living in private or collective households (i.e. retirement homes, prisons, etc.). In a second step, the sample was extended with all household members of those individuals sampled in the first step and living in private households. The final sample comprises a set of 305,019 individuals. Sample weights have been constructed to inflate the sample to the 2001 total population level and to correct for the overrepresentation of larger households which is due to the sampling method. For this sample, a data set with micro data from various administrative sources was constructed. Apart from some household characteristics taken from the National Register (age, sex, relationship between household members, region and population density in the residence area), the data set consists of variables taken from the 'Datawarehouse labour market and social protection'. At the time of writing, the data set we dispose of contains a) labour market income and a number of labour market characteristics for wage earners in either the private or public sector, b) some labour market characteristics and incomes of the self employed c) information on various social benefits such as unemployment benefits, sickness and disability benefits and pensions. All variables in our data set contain registrations for the tax benefit year 2001.

For the purpose of modeling labour supply we selected a subsample of households. The sub-

\footnotetext{
${ }^{2}$ Note that the minimum level of earnings is redundant since labour market legislation sets the minimum wage above the minimum threshold. The only cases in which the minimum level becomes relevant is for apprenticeships for which the minimum wage may be lower. Since 2004 the minimum threshold was therefore taken away altogether. Note also that the levels of the maximum benefits cited above are those for white collar workers. Blue collar workers enjoy slightly higher amounts given that they face a slightly higher contribution rate.

${ }^{3}$ The French Prime Pour l'Emploi (PPE) shares similar features, but the amount of the benefit is also a function of the family situation and the scaling with respect to working time is not linear, so that the benefit still delivers a part-time premium (Orsini, 2006b).
} 
sample is made of individuals in working age (18-65) available for the labour market, i.e. not (pre)retired, nor sick or disabled. For this purpose we used the age and the labour market status at the beginning of the fourth quarter. Youngsters under the age of 25 who are not employees, self employed or registered as unemployed are assumed to be in full-time education and not available for the labour market. Children over 25 with undefined professional status, on the other hand, are assumed to be inactive and thus potentially available for the labour market. This assumption allows us to neglect simultaneity issues of educational investment and labour supply. In modeling labour supply we also excluded the self employed, due to lack of information on the hours worked. This standard practice is not particularly harming in the current analysis since the Workbonus only affects employees. Such modeling hypothesis may however bring in significant biases in the analysis of reforms that affect the whole labour force - e.g. an income tax reform. Employees, unemployed and inactives are treated as having a flexible labour supply. For couples we of course also have the possibility of mixed cases. For example a household may consist of a self employed husband and of an employed wife, or vice versa. These groups are not modeled.

Besides the 'standard' cases of singles and couples there is a residual group of households which contains different types of families and forms of cohabitation: this includes homosexual couples or cohabiting flatmates, brothers and sisters or other relatives sharing a same housing arrangement, and mainly couples with grown up children also available for the labour market. From the labour supply perspective, this group tends to be rather heterogenous, and the degree of 'unity' of the household (i.e. the extent to which the income of one member influences the decisions of the other members) is unknown and/or difficult to deduce. In other words, it is not possible to determine whether labour supply should be modeled as an individual or joint decision. We therefore follow the bulk of the literature on ex-ante evaluations and decide not to model these households.

Table 2 summarises the selection process for the whole population while figure 2 gives a visual explanation of the selection procedure and of the modeling strategy. Following the selection we are able to model 32,521 couples, 14,710 single males and 13,574 single females, i.e. almost $80 \%$ and $70 \%$ of males and females available for the labour market. Table 3 provides descriptive statistics of the modeled samples.

The use of an administrative dataset for the purpose of labour supply estimation is unusual. Relying on administrative data has some clear advantages, typically the quality of the income information - at least as far as replacement incomes and earned income in the formal economy are concerned. On the other hand, there are also some disadvantages. The most prominent one is the lack of relevant information like the education level. Another important limitation is the definition of the labour market status of individuals. The latter relies entirely on the source of incomes. Individuals who do not receive pension benefits, unemployment benefits or sick and invalidity benefits and who are currently not earning any income from labour are automatically classified as inactive. The latter moreover are supposed to be available for the labour market. It is however likely that some of these individuals are working in the shadow economy, while some others are not available to the labour market due to a 'discouraged worker' effect. Arguably, information 
derived from income surveys might be affected by greater measurement error in some dimension, but the information on actual behaviour is likely to be more accurate. This and other differences should be kept in mind when comparing both the characteristics of the underlying population and the labour supply model estimates.

MIMOSIS is a microsimulation model for the Belgian social security and personal income tax system, running on the administrative dataset described above. Since the data go back to the tax benefit year 2001, the legislation that is currently modeled as baseline legislation, is the one of 2001. The current version of the model aims to cover 6 policy domains: a) social security contributions, b) unemployment benefits, c) sickness and disability benefits, d) family benefits, e) social assistance benefits and f) personal income taxes.

Through MIMOSIS it is possible to analyse the distributional impact of changes in the tax and benefit system, like, for example, the introduction and the extention of the Workbonus. Table 4 shows, for the whole population, the average household social security contributions that would be paid in each decile of equivalent household disposable income, if the Workbonus did not exist. ${ }^{4}$ The next two columns show the level of the SSCs paid in 2001 and the amounts of SSCs that would be paid in 2001, had the 2006 system been implemented in 2001. MIMOSIS is purely static and thus simulates only the immediate or 'day-after' effect, neglecting the agents' potential behavioural adjustments.

Workbonus 2001 is mainly in favour of the $3^{\text {rd }}$ and $4^{\text {th }}$ decile. The bottom deciles typically include elderly households with pensions as the main source of income. The extension of 2006 also benefits the $5^{\text {th }}$ and the $6^{\text {th }}$ decile. Note that in particular the 2006 extension has a considerable effect on the average disposable income. The increase in disposable income of the $3^{\text {rd }}$ and $4^{\text {th }}$ decile is in the order of $.55 \%$. Finally, for higher income households the effect of the work bonus approaches 0 in percentage terms. In absolute terms, however, the reduction in social security contributions paid is still significant, which provides evidence that low skilled workers may be found in all segments of the income distribution.

The use of a microsimulation model in this kind of analysis is not only limited to the static analysis. On the one hand, microsimulation allows to translate the complex real world tax benefit system into the budget constraints - a step that as we shall see is fundamental for the estimation of labour supply models. ${ }^{5}$ On the other hand, the underlying database with micro information on a representative sample of households or individuals allows to complement the standard aggregate results (e.g. for the budget) with a rich and detailed distributional analysis.

A key variable in the labour supply model is gross wage. For the individuals active in the labour market we determined the gross wage by dividing gross labour income during the 4th quarter by the number of contractual hours, two variables which are both registered by the Datawarehouse. For the unemployed and inactives, we first tried to reconstruct their gross hourly wage by retrieving the last recorded hourly wage for those who had been active on the labour market before as wage

\footnotetext{
${ }^{4}$ Deciles are constructed on the population of individuals using household disposable income adjusted with the squared root of household size to account for economies of scale.

${ }^{5}$ The - often hidden - interactions between different income components and eligibility rules need a level of detail in the program only available in a genuine microsimulation model.
} 
earner. If both current and past labour market information was lacking, we assumed the individual could at least obtain the minimum hourly wage (6.92 EUR in 2001). ${ }^{6}$ Overall the average gross hourly wage (either registered or reconstructed) amounts to 13,00 EUR (in 2001 prices).

Assuming that the hourly gross wage stays constant across different working time options, we computed gross labour income for discrete intervals of weekly labour supply. The intervals ranged from 0 to 55 hours, in steps of 5 hours. $^{7}$

\section{Modeling labour supply: two alternative characterisations}

\subsection{The conventional discrete choice modeling approach}

The standard discrete choice approach enables the researcher to straightforwardly apply quite general specifications of the utility function defined on a pre-selected discrete set of points on the individual's or the household's budget constraint. This approach is convenient because no marginal calculation is needed. Specifically, it enables the researcher to straightforwardly apply quite general specifications of the utility function and the budget constraint. However, it fails replicate the peaks on full-time and part-time hours that typically characterise the distribution of working hours (especially in continental Europe). Fixed costs of hiring workers, increasing returns to scale of the worker's production and the prevalence of standard employment contracts may explain the relative scarcity of some working time alternatives, especially in the Belgian and in other highly unionised labour markets. More importantly, however, the overall number of working opportunities varies across individuals: highly educated professionals are typically confronted with several job opportunities, whereas low skilled workers are constrained to choose among few jobs or may have no job offer at all.

As mentioned in the introduction, the conventional discrete choice approach is basically a version of the standard approach, and therefore cannot accommodate restrictions on the set of feasible jobs and explain peaks on full-time and part-time hours. This issue will be taken up in the econometric model proposed later in section 4.2. Let us however first introduce the conventional discrete choice modeling approach.

Let $U\left(C, H_{f}, H_{m}\right)$ denote the utility function of the household, where $H_{f}$ and $H_{m}$ are hours of work for the female and the male in the household, respectively. The finite set of possible values of working hours is denoted as $D_{f}$ and $D_{m}$. We assume that hourly wages are individual specific and do not vary across those possible working hours. $C$ is the household disposable income (or consumption in a static framework), corresponding to the chosen level of labour supply.It is a

\footnotetext{
${ }^{6}$ We are aware that the standard procedure to impute missing wages, is to estimate a wage equation (either a linear regression or a Heckman two stage wage equation). However, since one of the crucial explanatory variables of the wage equation, level of education, is missing we could not fall back on this technique. The imputation is relatively marginal for single males and males in couples (less than $7 \%$ of the sample. For single females the imputation concerns about $15 \%$ of the sample and for females in couple about $24 \%$ of the sample).

${ }^{7}$ The introduction of possible labour supply above the legal maximum of 38 hours a week for a single full-time job reflects the possibility of a combination of multiple parttime jobs. That people in practice do combine multiple jobs on the Belgian labour market is illustrated in Vermandere and Stevens (2002).
} 
function of the hours of work combination, i.e.

$$
C=C\left(H_{f}, H_{m}\right)=w_{m} H_{m}+w_{f} H_{f}+I-t\left(w_{m} H_{m}, w_{f} H_{f}, I\right)
$$

where $w_{r} r=m, f$ is the wage rate for gender $r, I$ is the household nonlabour income and $t()$ is the tax function. All the details of the tax/social security rules can be taken into account in this function.

Following the Random Utility Model (RUM) approach, the utility function for the household when the female and male works $H_{f}$ and $H_{m}$ hours respectively may be represented as:

$$
U\left(C, H_{f}, H_{m}\right)=v\left(C\left(H_{f}, H_{m}\right), H_{f}, H_{m}\right)+\varepsilon\left(H_{f}, H_{m}\right)
$$

where $v($.$) is a deterministic function which also depends on household observed characteristics.$ $\left\{\varepsilon\left(H_{f}, H_{m}\right)\right\}$ are random taste shifters. These random taste shifters are assumed to account for unobservable individual characteristics that affect preferences and will vary across households.

We assume that the random error terms $\left\{\varepsilon\left(H_{f}, H_{m}\right)\right\}$ are $i . i . d$. across all hours of work combinations and households with c.d.f. $\exp (-\exp (-x))$ for real $x$. Then it follows from well known results (see McFadden (1974)) that the probability that household chooses the combination of hours $\left(H_{f}, H_{m}\right)$ is given by:

$$
\begin{aligned}
P\left(U\left(C, H_{f}, H_{m}\right)\right. & \left.\geq U(C, x, y), x \in D_{f}, y \in D_{m}\right) \\
& =\frac{\exp \left(v\left(C\left(H_{f}, H_{m}\right), H_{f}, H_{m}\right)\right)}{\sum_{x \in D_{f}, y \in D_{m}} \exp (v(C(x, y), x, y))} \\
& =\frac{\psi\left(H_{f}, H_{m}\right)}{\sum_{x \in D_{f}, y \in D_{m}} \psi(x, y)},
\end{aligned}
$$

where $\psi\left(H_{f}, H_{m}\right)=\exp \left(v\left(C\left(H_{f}, H_{m}\right), H_{f}, H_{m}\right)\right.$.

As anticipated in the introduction, the above specification fails to reproduce the observed distribution of working hours. Typically,participation is under predicted and part-time positions are overpredicted. This pattern may be indeed explained by supply side factors alone, like fixed costs of labour supply. However, the fact that other working time alternatives are typically over predicted too, suggest that other factors may play a role. In particular technological and institutional constraints may lead to lower availability of job opportunities with non standard working hours. van Soest (1995) proposes an ad hoc adjustment, by introducing alternative specific dis-utility elements. The latter take the form of alternative specific dummies:

$$
U\left(C, H_{f}, H_{m}\right)=v\left(C\left(H_{f}, H_{m}\right), H_{f}, H_{m}\right)+c_{m}\left(H_{m}\right)+c_{f}\left(H_{f}\right)+\varepsilon\left(H_{f}, H_{m}\right) .
$$

van Soest (1995) suggest that the dummies may be interpreted as the higher search costs of relatively scarce job opportunities, but in the context of non dynamic structural modeling their economic interpretation is at least obscure and may capture both rationing and different nonpecuniary characteristics of jobs with non standard working hours requirements. The probability that household chooses the hours of work combination $\left(H_{f}, H_{m}\right)$ is then given by: 


$$
\frac{\psi\left(H_{f}, H_{m}\right) \exp \left(c_{m}\left(H_{m}\right)\right) \exp \left(c_{f}\left(H_{f}\right)\right)}{\sum_{x \in D_{f}, y \in D_{m}} \psi(x, y) \exp \left(c_{m}(y)\right) \exp \left(c_{f}(x)\right)}
$$

\subsection{The model with choice among latent job opportunities}

In the current subsection an alternative modeling framework is introduced ${ }^{8}$. In contrast to the approach described above where the household is restricted to have preferences solely over combinations of total consumption and hours of work of the partners, we allow the agent in addition to have preferences over nonpecuniary job attributes such as the nature of the job-specific tasks to be performed, and location of the workplace, etc, which are assumed to be known by the household, but unknown to the econometrician.

Let $U\left(C, H_{f}, H_{m}, z\right)$ denote the utility function of the household, where $C, H_{F}$ and $H_{m}$ are defined as above and $z=\left(z_{F}, z_{M}\right)$ indexes the combination of jobs for the female and male in the household. We assume that

$$
U\left(C, H_{f}, H_{m}, z\right)=v\left(C\left(H_{f}, H_{m}\right), H_{f}, H_{m}\right)+\varepsilon(z) .
$$

where $v($.$) is a positive deterministic function and \{\varepsilon(z)\}$ are positive random taste shifters. The random taste shifters are assumed to account for unobservable individual characteristics and nonpecuniary job-type attributes that affect utility, and hence will vary both across households and job opportunities. Note that this is different from the standard discrete hours labor supply discussed in section 4.1, where the random taste shifters are assumed to vary across household and hours of work. $\varepsilon(z)$ are assumed to be i.i.d. across job combinations and household with $\exp (-\exp (-x))$ for real $x$. For a given job opportunity $z_{r} r=f, m$, associated hours of work is assumed fixed. Let $B\left(H_{f}, H_{m}\right)$ denote the set of feasible job opportunities with hours of work combination $\left(H_{f}, H_{m}\right)$.

The probability of household of choosing a particular combination of jobs $z$ then is given by:

$$
\begin{aligned}
P\left(U\left(C, H_{f}, H_{m}, z\right)\right. & \left.\geq U(C, x, y, q), x \in D_{f}, y \in D_{m}, q \in B(x, y)\right) \\
& =\frac{\exp \left(v\left(C\left(H_{f}, H_{m}\right), H_{f}, H_{m}\right)\right.}{\sum_{x \in D_{f}, y \in D_{m}} \sum_{q \in B(x, y)} \exp (v(C(x, y), x, y))} \\
& =\frac{\psi\left(H_{f}, H_{m}\right)}{\sum_{x \in D_{f}, y \in D_{m}} \sum_{q \in B(x, y)} \psi(x, y)}
\end{aligned}
$$

The above equation clearly resembles equation 1 . In the standard model, however, working hour requirements univocally characterise each job alternative. The set of available alternatives is therefore defined by all possible combinations of female and male working time alternatives, which in terms implies that the empirical counterpart of equation 1 is the observed fraction of couples where the female and the male work $H_{f}$ and $H_{m}$ hours respectively.

\footnotetext{
${ }^{8}$ For a more complete description we refer to Dagsvik and Strøm (2006) and Dagsvik and Jia (2008).
} 
In the current version, the working time requirements do not univocally characterise the choice set. For each combination of working time requirements there will be a set of alternative opportunities, each being characterised by unobservable nonpecuniary characteristics. Moreover the size of the choice set is unknown. The empirical counterpart of the above equation is therefore not observable.

What is observed, however, is the empirical counterpart of the probability that a household chooses a combination of jobs with given working time requirements $H_{f}$ and $H_{m}$. The latter is simply the sum of the probabilities of all jobs having $H_{f}$ and $H_{m}$ hours as working time requirements,

i.e.:

$$
\sum_{z \in B\left(H_{f}, H_{m}\right)} \frac{\psi\left(H_{f}, H_{m}\right)}{\sum_{x \in D_{f}, y \in D_{m}} \sum_{q \in B(x, y)} \psi(x, y)}
$$

Since the structural part of the utility is not affected by the unobserved non pecuniary characteristics of the jobs, we may rewrite the above expression as:

$$
\frac{\psi\left(H_{f}, H_{m}\right) M\left(H_{f}, H_{m}\right)}{\sum_{x \in D_{f}, y \in D_{m}} \psi(x, y) M(x, y)}
$$

where $M\left(H_{f}, H_{m}\right)$ is the total number of job alternatives available to the female and to the male in the household that require $H_{f}$ and $H_{m}$ hours of work.

We assume further that the choice sets of jobs offered to the female and to the male, respectively, are independent. The latter assumption may be restrictive because husband and wife may face the similar constraints on the choice of jobs due to the structure of the local labor market. It is however easy to allow the choice sets of husband and wife to be correlated, but a discussion of this extension will be left for another occasion. Given this independence assumption, we have:

$$
M\left(H_{f}, H_{m}\right)=M_{f}\left(H_{f}\right) M_{m}\left(H_{m}\right),
$$

where $M_{r}\left(H_{r}\right)$ denote the number of feasible job opportunities with hours of work $H_{r}$ for gender $r$. Unfortunately, we do not dispose on external information the number of available job opportunities, nor do we know the number of non working opportunities. ${ }^{9}$ However, what we are really interested in the relative distribution of job opportunities across the different levels of hours of work, and relative size of the market opportunity set with respect to the non working opportunities. Both are identified given our framework. To see this, we write that $M_{r}\left(H_{r}\right)=\tilde{\theta}_{r} g_{r}\left(H_{r}\right)$ for $H_{r}>0$, where $\tilde{\theta}_{r}=\sum_{x>0} M_{r}\left(H_{r}\right)$ is the total number of feasible market opportunities available to gender $r$, and $g_{r}\left(H_{r}\right)=M_{r}\left(H_{r}\right) / \sum_{x>0} M_{r}\left(H_{r}\right)$ the share of available jobs at given working hours $H_{r}$. The terms $g_{r}\left(H_{r}\right) H_{r}>0$ are called opportunity densities.

Under these assumptions, for $H_{f}>0, H_{m}>0$, the probability equation (3) can now be written

\footnotetext{
${ }^{9}$ Identification cannot be achieved through parametric assumptions that impose structures on $M_{r}\left(H_{r}\right)$ either, since the scale parameters are not identified in logit-type model.
} 


$$
\begin{gathered}
\frac{\psi\left(H_{f}, H_{m}\right) \tilde{\theta}_{f} g_{f}\left(H_{f}\right) \tilde{\theta}_{m} g_{m}\left(H_{m}\right)}{\psi(0,0) M_{f}(0) M_{m}(0)+\sum_{x>0} \psi(x, 0) \tilde{\theta}_{f} g_{f}(x) M_{m}(0)+\sum_{y>0} \psi(0, y) M_{f}(0) \tilde{\theta}_{m} g_{m}(y)+\sum_{x, y>0} \psi(x, y) \tilde{\theta}_{f} g_{f}(x) \tilde{\theta}_{m} g_{m}(y)} \\
=\frac{\psi\left(H_{f}, H_{m}\right) g_{f}\left(H_{f}\right) g_{m}\left(H_{m}\right)}{\psi(0,0) \theta_{m} \theta_{f}+\sum_{x>0} \psi(x, 0) g_{f}(x) \theta_{m}+\sum_{y>0} \psi(0, y) \theta_{f} g_{m}(y)+\sum_{x, y>0} \psi(x, y) g_{f}(x) g_{m}(y)}
\end{gathered}
$$

where $\theta_{r}=M_{r}(0) / \tilde{\theta}_{r}=M_{r}(0) / \sum_{x>0} M_{r}\left(H_{r}\right)$. Similar results can be obtained for the case when $H_{f}=0$ or $H_{m}=0$.

From equation (4), we see that under the restriction that $g_{r}()$ is a distribution function over the possible positive hours of work, both $\theta_{r}$ and $g_{r}($.$) are identified. g_{r}($.$) describes the distribution$ of job opportunities across the different levels of hours of work. The term $\theta_{r}$ can be interpreted as a measure of relative size of the market opportunity set with respect to the non working opportunities, which is assumed to be individual specific. In the empirical application part of this analysis, we assume that $\theta_{r}$ is a function of individual characteristics such as age, region dummy and wage rate. 10

Note that the conventional discrete model presented in the previous section, can be viewed as a special case of the current model. In the standard discrete choice approach the opportunity density is simply assumed uniformly distributed and $\theta_{r}=1$.

The ad hoc correction with alternative specific dis-utilities can be seen as a reformulation of our framework with. $g_{r}(x)=\exp \left(c_{r}(x)\right)$ and $\theta_{r}=\exp \left(c_{r}(0)\right)$. In other words, our framework offers a theoretical rationale and alternative interpretation for this practice.

\subsection{Functional forms for utility representation}

As stated above, identification is conditional on the a priori specification of the utility function. Current quantitative economic research often suffers from the lack of theoretical principles on which assumptions about functional forms of the utility function can be made. The standard approach in empirical analyses is therefore to simply assume a given functional form, or worse to 'let the data determine' functional forms within ad hoc selected parametric classes (including so-called flexible functional forms). This is clearly unsatisfactory in the context of structural modeling. Structural modeling should rely on a modeling framework explicitly derived from justified (or justifiable) assumptions on the working of the economy and not on a trial-and-error procedure determining which model best reproduces the observed data. ${ }^{11}$

\footnotetext{
${ }^{10}$ Note that the we can extend our model to account for so called dis-utility of working. However, in this case, we will not be able distinguish the dis-utility of working from the working opportunities measure $\theta$ given the labor supply data typically available. Stated preference data such as self reported desired hours of work can be useful in this respect. For example Bloemen (2008) uses subjective information on desired weekly working hours as a source of information in addition to observed working hours to to separate preferences from job offer distributions in a job search model.

${ }^{11}$ This point is also stressed by Aaberge et al. (2006): in a simulation exercise they show that different econometric specifications are compatible with the 'true model', i.e. the econometric specification used to generate the data. The fit of the data, may therefore not be a criterion to select amongst alternative specifications. At the same time, however, the different specifications lead to substantially different predictions of effects under different tax regimes.
} 
In the preceding sections we have proposed a particular representation of the labor supply choice probabilities in terms of functions that represent preferences and opportunities. We now turn the attention to the functional specification of the structural utility term.

Dagsvik and Strøm (1989) for example applied a second degree polynomial specification of the deterministic part of the utility function, given as:

$$
v\left(C, H_{f}, H_{m}\right)=\alpha_{c} C^{2}+\beta_{c} C+\alpha_{f} L_{f}^{2}+\beta_{f} L_{f}+\alpha_{m} L_{m}^{2}+\beta_{m} L_{m}+\beta_{c f} C L_{f}+\beta_{c m} C L_{m}+\beta_{f m} L_{f} L_{m}
$$

where $\alpha_{c}, \alpha_{f}$ and $\alpha_{m}$ are negative and where $L_{f}=1-H_{f} / T$ and $L_{m}=1-H_{m} / T$ represent the hours of leisure, normalised with respect to the total time endowment $T$, which is set at 80 hours per week.

This specification has the advantage of being flexible and easy to estimate because it is linear in parameters and has therefore been extensively applied, see Blundell et al. (2000), Bargain and Orsini (2006) and Bonin, Kempe, and Schneider (2002). Van Soest, Das, and Gong (2002) applied even a more general polynomial specification (up to fifth degree).

In empirical analysis the parameters on consumption and male and female leisure are specified as linear functions of individual and household characteristics. However, the drawback with this specification is that it is not always globally concave and monotone.

Dagsvik and Strøm (2006) argue that implications from the theory of psychophysical measurement and dimensionality analysis may be used to derive more plausible functional forms. As it appears in the literature of psychophysical measurement, numerical representations of sensory perceptions and physical stimuli can only be measured up to a scale. The latter implies that - once basic needs (subsistence) are fulfilled - the absolute levels of quantities tend not to be essential, rather the individuals relate to relative consumption levels. The utility function should not contain a satiation point and ordering of utilities should not be dependent on scale transformations. These assumptions may be satisfied by the Box-Cox utility function:

$$
V\left(C, H_{f}, H_{m}\right)=\beta_{c} \frac{\left(\left(C-C_{0}\right)^{\alpha_{c}}-1\right)}{\alpha_{c}}+\beta_{f} \frac{\left(L_{f}^{\alpha_{f}}-1\right)}{\alpha_{f}}+\beta_{m} \frac{\left(L_{m}^{\alpha_{m}}-1\right)}{\alpha_{m}}+\beta_{f m} \frac{\left(L_{f}^{\alpha_{f}}-1\right)\left(L_{m}^{\alpha_{m}}-1\right)}{\alpha_{f} \alpha_{m}}
$$

where $C_{0}$ represents a subsistence level of income. If $\alpha_{c}<1, \alpha_{f}<1, \alpha_{m}<1$ and $\beta_{c}>0$ and $\beta_{f}$ and $\beta_{m}$ are positive and sufficiently large, then utility is increasing in $C$ and decreasing in $L_{f}$, $L_{m}$ for fixed $C$.

The specifications for singles (males and females) are similar to the above equations, although the structural utility only contains one leisure term.

\section{$5 \quad$ Estimation results}

The labour supply is estimated separately for couples, single males and single females. For each group, four different models are estimated. Model I is the standard discrete choice model as 
defined in equation (1); model II is the standard model with ad hoc adjustment for the non standard working time requirements as defined in equation (2) and model III is the alternative specification defined by equation (4). The latter models have been estimated using the quadratic specification of the utility function defined by (5). Finally, model IV uses the model of equation (4), in conjunction with the Box-Cox utility function defined in (6).

Table 5 presents the results of the model I, and figures 3, 4, 5 and 6 present the fit of the observed distribution of working hours for males and females in couple and for single males and females respectively. As anticipated, model I performs very badly in fitting the data. In particular the model predicts the inactivity peak and a more or less normal distribution of working hours along the range 5 to 55 , but does not capture the full-time peak for males and the part-time and fulltime peak for females. Moreover, inactivity is strongly underpredicted, whereas the non standard working alternatives are overpredicted. Although the model fails to reproduce the distribution of working hours, it predicts correctly the average labour supply over the whole sample.

Model II uses dummies in order to fit the part-time and full-time peaks. Additional dummies were introduced for marginal part-time ( 5 to 15 hours hours per week), the $3 / 4$ full-time (25 to 35 hours per week) and over-time (45 to 55 hours per week). Through different specifications, it was found that 10 dummies ( 5 for females and 5 for males) were necessary to fit the observed data. This ad hoc way to 'calibrate' the model on the observed peaks in the distribution of working hours is not uncommon in the empirical literature, see amongst others Haan (2006), Bonin, Kempe, and Schneider (2002).

The last rows in table 5 and table 6 show the percentage of observations with a positive derivative of the utility function with respect to consumption and leisure. The theoretical consistency of the model, requires that the derivatives with respect to income are positive. In the estimation, in fact, we only consider the points on the budget constraint frontier, under the assumption that these points are always preferred to the internal points. If households prefer less income to more income the theoretical consistency of the model would vanish.

The negative derivatives with respect to leisure, on the other hand, are less harming and may be caused by different factors. Working is a key element of integration in our societies and inactivity is often stigmatised. Some individuals could therefore find higher utility in renouncing to some hours of leisures. Indeed this implies that some individuals may have an internal saturation point with respect to leisure.

In model I almost all cases have positive derivatives with respect to consumption and leisure (at the chosen hours supplied). The negative coefficient on income square is supposed to capture the decreasing marginal utility of income. The coefficients on the squared leisure terms of single males and females, however, are not negative which imply that the utility function is not concave in leisure.

In model II the coefficients have the expected sign, but a large share of cases have a negative first derivative with respect to leisure and a very few cases also with respect to consumption. The cases with negative derivative with respect to consumption typically correspond to households with 
outlying income levels. However, a few outliers turn out to have an internal saturation point. As long as the number of cases is marginal this should not represent a major concern. The model could be reestimated leaving out the outliers and would substantially deliver the same results.

Arguably, non well behaved estimated preferences with respect to leisure may be caused by a misspecification of the opportunity sets - rather than a consistent representation of true households' preferences. In particular, inactivity may well be the result of rationing, while not all job opportunities may be equally available to all individuals. Let us therefore turn to models III and IV.

Model III relies on the specification defined by equation (4) - which is supposed to correct for latent and heterogeneous choice opportunities - in conjunction with a quadratic specification of the utility function. The fraction of feasible jobs is assumed to depend on individual characteristics such as productivity (for which the wage rate is a proxy), age, age squared and region of residence. Feasible jobs are then assumed to be homogenously offered for non standard working time requirements with a part-time and full-time peak for females and a full-time and a 35 hours peak for males. Table 7 shows the estimates of the preference structure of such specification. The share of households presenting an internal saturation point with respect to income increases marginally for all groups. For single females, however, the share of households with a negative first derivative of the utility function with respect to income is far from being marginal. At least for this group model III should therefore be discarded. However also the share of households having an internal saturation point with respect to leisure increases.

This is not entirely surprising: the quadratic model is extremely flexible without additional constraints on the coefficients. Adding a flexible specification of the opportunity set increases the degrees of freedom and thus the fit of the model, as it is witnessed by figures 3, 4, 5 and 6 and the strong decrease in the log-likelihood. As previously argued, nevertheless, the fit of the model is not an appropriate indicator in the context of structural modeling. An acceptable fit of the data may only be considered as a prerequisite for a labour supply model, but does not imply that the model will perform well in predicting labour supply behaviour when the budget constraint is modified.

The Box-Cox utility function is less flexible than the quadratic specification and, for given values of the parameters it is globally increasing and concave in both income and leisure. The basic intuition is that a constrained representation of the preference structure entails a clearer separation of the factors affecting preferences and the factors affecting opportunities.

In model IV we combine the model specified in equation (4) with this more restrictive Box-Cox utility function. The 'subsistence' level of leisure is fixed at 25 hours per week. The 'subsistence' level of income $C_{0}$ is set at $4000 \mathrm{EUR} /$ year for a single person household. We multiply the subsistence level by $\sqrt{N}$, where $N$ is the number of persons in the household, to account for economies of scale in consumption in households with more than one person. We also tried a model with an endogenous level of 'subsistence' income, but this failed to converge. The 'subsistence' income approximately corresponds to the yearly minimum income guarantee in 2001. Just like in the quadratic specification, some coefficients, namely $\beta_{f}$ and $\beta_{m}$ are modeled as a linear combination 
of observed individual and household characteristics. The estimates of this model are presented in table 8. The value of the estimated parameters on consumption and leisure imply that the utility function is globally concave for all modeled groups both with respect to income and leisure. Moreover, model IV also fits the data well.

As already stated the fit of the data should not be a criterion for discriminating amongst competing models, although arguably a good fit of the data should be considered as a prerequisite of a good model. The superiority of model IV, therefore, derives from the fact that differently from the other specifications, it is build from clearly stated and justified assumptions on the working of the economy and on the behaviour of agents, rather than on ad hoc representation of the opportunity set and of the preference structure.

In table 9 we compare the elasticities derived under the 4 different specifications. Elasticities are derived numerically, by increasing the hourly wage by $1 \%$ and computing the expected change in aggregate labour supply. In the following we will focus on the results of model II and model IV. Model I is entirely discarded since it predicts a distribution of hours which is inconsistent with the data, whereas model III is theoretically inconsistent for a large group of single females. Model II on the other hand is also retained in order to stress the different predictions of the standard model and of the alternative specification proposed.

Model II predicts labour supply elasticities at around .4 for single females and males (either in couple or singles), whereas for females in couple, the labour supply elasticity is estimated at .76. This result is consistent with several studies surveyed in Blundell and MaCurdy (1999): single males and males in couples tend to have lower labour supply elasticities than secondary earners, i.e. females in couples. Overall, the estimated elasticities are higher than recent estimates for other countries: Bonin, Kempe, and Schneider (2002) and Haan and Steiner (2005) have estimates of around .20 and up to .35 for German males and females in couples. Although for females in couples Aaberge, Colombino, and Strøm (2004) and van Soest (1995) also find particularly high values, ranging from .60 to .70 (respectively for the Netherlands and Italy). Their estimated labour supply elasticities for primary earners, however, are in the range of .1.

As shown in Bargain et al. (2006) not accounting for labour demand constraints induces an upward bias in the estimates of labour supply elasticities. Model IV predicts lower labour supply elasticities: .28 and .46 for males and females in couples respectively and .12 and .21 for single females and single males. Model III also predicts lower labour supply elasticities for couples (.31 and .22 for females and males respectively) and for single males (.17).

The fact that single females have the lowest labour supply elasticities is at odds with the experience of other countries - in particular the UK. It should be noted, nevertheless, that in Belgium means tested aid for single parents, i.e. mostly single mothers, is rather limited. Contrary to other countries, in fact, single mothers do not receive significantly higher income support. At the same time their unemployment benefits tend to be lower due to weaker labour market attachment. It is therefore likely that a relatively higher share of unemployed single females are affected by rationing on the labour market. On the other hand, the average household size of single females 
is 1.45 which implies a higher subsistence level of income. This factor is likely to limit for single mothers the number of choices actually available, given that only alternatives with positive income are considered as feasible.

Finally it should be noted that the elasticities estimated in accordance to model IV are also higher than estimates for Belgium based on a standard model of labour supply (Orsini, 2006a). This is only partially surprising: former estimates are in fact based on survey data. In the administrative dataset at hand a higher share of non working individuals are classified as available for work. It is likely that a share of the latter would declare themselves as not available for work in survey data due to the 'discouraged worker' effect. As shown in Bargain et al. (2006), elasticities are mostly driven by the participation effect, which implies that population sub-groups with higher inactivity rates tend to have higher elasticities.

\section{$6 \quad$ Results from policy simulations}

Table 10 shows the estimated impact of the changes in the Workbonus: the first two rows relate to an abolishment of the work bonus and the second two rows relate to an extension from the 2001 to its 2006 level. The effects are divided into an aggregate change in labour supply (i.e. change in hours, although expressed in full-time equivalent - FTE) and a change in the number of participants and are presented separately for the traditional model (model II) and for the alternative modeling framework (model IV). As could be expected by the diverging labour supply elasticities, the two models give quite different predictions. Let us consider first the abolishment of the Workbonus 2001. Should the subsidy be removed, according to the standard model labour supply would drop by 15000 FTE units, whereas participation would decrease by 17000 units. Females in couples are the main group driving the change in labour supply, since they account for an increase in FTE of 6000 units and an increase in participation of 7000.

The changes predicted by the alternative models go in the same direction, but the size of the effect is much smaller: labour supply would decrease by only 7000 FTE unit, whereas participation would decrease by about 8000 unit in total. With respect to the composition of the change, the models predict a similar pattern. The change in FTE units is driven by females in couples, then males in couples and to a lesser extent to singles. The predicted change in participation and hours supplied for single females is much smaller than the prediction according to model II, which is in line with the large differences in the estimates of labour supply elasticities for this subgroup.

When we look at the effect of the extension of the Workbonus to its 2006 level, the divergence between the prediction of the two models persist. Model II predicts a change in labour supply of about 23000 FTE, whereas according to model IV the increase should be in the order of 12000 FTE. With respect to participation the two models predict an increase of 25000 and 13000 units respectively.

Note that the estimates of of model IV are not too far from Orsini (2006a): in that paper the estimated labour supply effect for couples ranges from 5200 to 8800 FTE units, whereas here the change is in the order of 8000 units for couples. The model used in Orsini (2006a), nevertheless is 
a variation of a model II. As argued before, however, the extent of rationing could probably play a different role in administrative and survey data, since in survey data rationed individuals may declare themselves as out of the labour force due to a 'discouraged worker' effect.

Note finally that the increase in participation and in FTE units goes hand in hand in both scenarios. As argued in the introduction, this is a peculiar effect of targeting the benefit on low FTE earnings, rather than low current earnings. The last expansion of the Workbonus replaced a tax credit on low earned income. Orsini (2006a) shows that compared to the Workbonus, the tax credit would have had a higher participation effect, but a smaller impact on aggregated labour supply. Indeed the tax credit increase the incentives to take up work for the low skilled, but also for the medium skilled willing to work part-time. At the same time, medium skilled workers in employment would reduce labour supply, finding partial compensation from the tax credit. Since the Workbonus is conditional on hourly wage, this negative effect at the intensive margin is avoided.

Figure 7 shows the percentage change in participation and in aggregate labour supply by income decile according to the two models. In particular the left axis indexes the change in aggregate labour supply, whereas the right axis indexes the change in participation. The percentage change is expressed with respect to total participation and total labour supply in each income decile. The picture clearly show that the Workbonus increases participation in the lower income deciles, in the first 4 income deciles. The aggregate effect, however, is positive for all deciles. The first order (static) distributional impact is reinforced by the second order (behavioural) effect. Redistributive and incentive effects are therefore mainly directed to the bottom part of the income distribution.

Table 11 presents the costs of the 2006 increase in the Workbonus. The first row shows the cost of the Workbonus as derived from official statistics. Based on the data of the Belgian National Social Security Office we have computed the reduction of revenue from social security contributions due to the 2006 expansion as the difference between the 2006 figure and the 2001 figure (inflated to 2006 values). In the second row we show the reduction in social security contributions simulated by MIMOSIS. This figure is derived simply by applying the 2006 rules on the 2001 baseline. The 443 million EUR predicted by MIMOSIS are close to the official figure of 481 million EUR, considering that the microsimulation model does not account for changes in demographic factors and other economic circumstances - including additional labour market participation induced by the benefit itself.

Once we account for behavioural adjustments, the cost increases substantially according to model II (524 million EUR), while model IV predicts an aggregate cost of 483 million EUR which is very close to the observed cost of the measure. ${ }^{12}$

Table 12 presents the cost per additional FTE unit and per additional participant of the 2001 and 2006 extensions, as well as the forecasted cost of the speculative further extension described above. The cost with respect to participation (total budgetary cost divided by the number of additional participants) is estimated to be in the range of 11430 EUR/year (model II) to 18404

\footnotetext{
${ }^{12}$ The change in revenue from social security contributions is not the true cost of the reform. Following the reduction in social security new participants would not only stop collecting their unemployment or income assistance benefits, but they also pay social security contributions and personal income taxes. These effects are not considered here.
} 
EUR/year (model IV) for the 2001 Workbonus and in the range of $21015 \mathrm{EUR} /$ year (model II) to 40330 EUR/year (model IV) for the 2006 Workbonus. Clearly further expansions of the measure would imply higher budgetary cost per additional job created.

The above figures may be compared with estimates obtained for similar activation measures implemented in other EU countries. Orsini (2006b) reviews a series of evaluation of 'Making Work Pay': according to estimates based on the reviewed works the cost of activation ranges from about 250000 EUR/year for the WFTC to about 120000 EUR/year for the French PPE. ${ }^{13}$ Moreover it should be noted that some activation measures, as the German Mini-job reform despite having a positive effect on participation, tend to have an overall negative effect on labour supply in terms of FTE. This is explained by the fact that the subsidies are targeted on some household income concept rather than on individual earnings or the wage rate.

The low budgetary cost of the Workbonus should nevertheless not lead to overoptimistic conclusions. The relevant element for comparison should be the 'benefit' of an additional worker. A proxy for that could be given by the average productivity of a worker. According to recent statistics the average labour productivity of the Belgian worker is in the order of $67000 \mathrm{EUR} /$ year. For low skilled workers, however, the productivity is likely to be lower. Nevertheless it is dubious that productivity is the relevant benefit indicator in a cost-benefit analysis.

A political discussion on further extension of the Workbonus calls for an improved understanding of the benefits of increased employment, including the effects on the income distribution and the possible positive externalities stemming from the mainstreaming of marginalised groups. Economists, in particular, should devote more attention to the benefit side in the evaluation of policies aiming at making work pay. At the same time, an assessment of a particular reform and not just an estimate of its potential impact on the labour force, would be easier in a balanced budget context. Unfortunately the public debate is often silent over the way a specific measure is financed and subsidies and tax cuts tend to be presented as 'manna from heaven'.

Note that the above considerations are based exclusively on the results of the ex-ante evaluation. It would be interesting to validate the results with an ex-post evaluation. Unfortunately no data is yet available for estimating the effect on employment based on a difference in difference approach. The data will probably be available in the near future. Nevertheless, it seems difficult to think of a valid comparison group for the evaluation of the Workbonus. In a difference in difference methodology, the comparison group should share the same characteristics of the treated group apart of course from the eligibility to the subsidy. This implies that the two groups may be considered to be equally affected by changes in the economic circumstances - a hypothesis which seems quite unlikely given that the two groups are in two different segments of the wage distribution.

\footnotetext{
${ }^{13}$ Of course the above figures are also affected by the underlying modeling framework and sample selection. Moreover the costs also reflect differences in the preference structure and in the institutional settings. Nevertheless the figures give an order of magnitude of the 'efficiency' of similar MWP measures implemented in EU countries.
} 


\section{Conclusions}

This paper relies on a sample of administrative data and on the microsimulation model MIMOSIS to evaluate ex-ante the effect of the Belgian Workbonus, a subsidy on social security contributions of employees aimed at supporting the employment of low skilled workers. In the first part of the paper we have discussed and tested different specifications of the labour supply model. The first specification fails to capture the demand side and institutional constraints that drive the presence of part-time and full-time peaks in the distribution of hours supplied. The ad hoc specification proposed by van Soest (1995) (model II) produced a good fit of the observed data. Model III combines the quadratic specification of the utility function with an improved representation of the opportunity set. This model also produced a good fit but clearly shows the limitation of the quadratic specification of the utility. The share of households with negative derivative of utility with respect to consumption increases substantially and can no longer be neglected - at least for the group of single females. The quadratic model combined with heterogeneity in job opportunities gives rise to an over-parameterised model which fits the data extremely well, but fails to preserve economic consistency.

Model IV uses a Box-Cox utility function consistent with psychophysical evidence on the behaviour of agents. Moreover, the results show that the data support the modeling framework. Model II and model IV were both used for assessing the Workbonus. Unfortunately, it is not possible to discriminate between model II and model IV, since tests based on the fit of the data should not be considered as valid selection criteria in the context of structural modeling. We argue however that the superiority of model IV comes from its reliance on plausible hypothesis on the working of the economy as well as on a set of (accepted) assumptions of agents' behaviour. Finally results are presented using both model II and model IV, as this allows us to stress the sensitivity of the results on the modeling framework.

The 2006 increase in the Workbonus is likely to have increased participation by 13000 to 25000 units (according to model IV and model II respectively). Having computed the budgetary cost of the reform (before and after behavioural responses) it is possible to derive an efficiency measure of the Workbonus. In particular the cost per additional participant were estimated to be in the order of 21015 and 40330 EUR/year for model II and model IV respectively. Although the figures are quite different they are far below the estimated cost of instruments like the British WFTC (over 200000 EUR/year) or the PPE (around 120000 EUR/year).

The Belgian Workbonus remains so far a unique case of individualised subsidy based on the wage rate - rather than on earnings. This allows to target low skilled workers and screen out individuals with a higher preference for leisure. At the same time workers with higher wage rates cannot reduce their working time in order to enter in the benefit range.

It should nevertheless be stressed that the Workbonus is particularly suited for the Belgian economic and institutional framework: the presence of the minimum wage coupled with highly centralised wage bargaining procedures should reduce the risk that employers rip the benefit of the reform by offering lower gross earnings to Workbonus-workers. Another possibility is that 
firms misreport the number of hours worked. By declaring more contractual hours than those actually worked, an employer could effectively offer a lower wage. While the possibility of such behaviour should not be excluded ex-ante, we argue that its aggregate effect should be negligible. Nevertheless some ex-post analysis in the following years should allow to verify to what extents employers have benefited from the Werkbonus possibly also through illegal behaviour.

Should the ex-post analysis confirm that agents have confirmed to legislation, it would be interesting to explore to what extent other elements of the tax and benefit system could be refocused on the wage rate - rather than on earned income. The Belgian experience should therefore deserve greater attentions by policy makers in European countries that share institutional and labour market characteristics comparable to the Belgian ones. 
Tab. 1: The Belgian tax reform and the employment bonus

\begin{tabular}{|c|c|c|c|}
\hline Year & Gross monthly earnings (FTEE) & White collar workers & Blue collar workers \\
\hline \multicolumn{4}{|l|}{2000} \\
\hline & $\begin{array}{c}<842.84 \\
\geq 842.84 \text { and }<1053.55 \\
\geq 1053.55 \text { and }<1214.68 \\
\geq 1214.68\end{array}$ & $\begin{array}{c}0 \\
64.45 \\
64.45-(0.40 *(\text { FTEE}-1053.55)) \\
0\end{array}$ & $\begin{array}{c}0 \\
69.61 \\
69.61-\left(0.43^{*}(\text { FTEE-1053.55) })\right. \\
0\end{array}$ \\
\hline \multicolumn{4}{|l|}{2001} \\
\hline & $\begin{array}{c}<859.69 \\
\geq 859.69 \text { and }<1125.19 \\
\geq 1125.19 \text { and }<1340.11 \\
\geq 1340.11\end{array}$ & $\begin{array}{c}0 \\
81.8 \\
81.8-\left(0.3806^{*}(\text { FTEE }-1125.19)\right) \\
0\end{array}$ & $\begin{array}{c}0 \\
88.35 \\
88.35-\left(0.4111^{*}(\text { FTEE-1125.19) })\right. \\
0\end{array}$ \\
\hline \multicolumn{4}{|l|}{2006} \\
\hline & $\begin{array}{c}<1258.88 \\
\geq 1258.88 \text { and }<2076.63 \\
\geq 2076.33\end{array}$ & $\begin{array}{c}140 \\
140-\left(0.1712^{*}(\mathrm{FTEE}-258.88)\right) \\
0\end{array}$ & $\begin{array}{c}151.2 \\
151.2-(0.1849 *(\text { FTEE-1258.88) }) \\
0\end{array}$ \\
\hline
\end{tabular}

FTEE is full time equivalent gross monthly earnings.

Amounts are expressed in EUR/month.

Tab. 3: Descriptive statistics (modeled subsamples)

\begin{tabular}{|c|c|c|c|c|}
\hline & \multicolumn{2}{|c|}{ Singles } & \multicolumn{2}{|c|}{ Couples } \\
\hline & Males & Females & Males & Females \\
\hline \multicolumn{5}{|l|}{ Demographics } \\
\hline Household size & 1.05 & 1.45 & \multicolumn{2}{|c|}{3.14} \\
\hline Children under 3 & 0.00 & 0.05 & \multicolumn{2}{|c|}{0.19} \\
\hline Children from 3 to 6 & 0.01 & 0.07 & \multicolumn{2}{|c|}{0.19} \\
\hline Children from 6 to 12 & 0.02 & 0.15 & \multicolumn{2}{|c|}{0.37} \\
\hline Children from 12 to 23 & 0.03 & 0.15 & \multicolumn{2}{|c|}{0.38} \\
\hline Age of male (head) & 35.05 & - & \multicolumn{2}{|c|}{40.82} \\
\hline Age of female (head/spouse) & - & 37.18 & \multicolumn{2}{|c|}{38.68} \\
\hline Living in Wallonia & 0.33 & 0.34 & \multicolumn{2}{|c|}{0.31} \\
\hline Living in Flanders & 0.53 & 0.50 & \multicolumn{2}{|c|}{0.62} \\
\hline Living in medium cities & 0.53 & 0.52 & \multicolumn{2}{|c|}{0.60} \\
\hline Living in big cities & 0.35 & 0.36 & \multicolumn{2}{|c|}{0.25} \\
\hline \multicolumn{5}{|l|}{ Labour Supply } \\
\hline Hours worked (all) & 25.26 & 20.35 & 30.29 & 18.77 \\
\hline Hours worked (population in employment) & 33.99 & 32.34 & 35.67 & 29.67 \\
\hline \multicolumn{5}{|l|}{ Hourly Wages } \\
\hline Hourly wage (all) & 11.77 & 10.69 & 14.34 & 10.93 \\
\hline Hourly wage (population in employment) & 12.73 & 12.14 & 15.12 & 12.46 \\
\hline
\end{tabular}

Tab. 4: Change in social security contributions paid and in disposable income by equivalent income decile

\begin{tabular}{cccccc}
\hline \hline \multicolumn{5}{c}{ Social security contributions paid (EUR/year) } & \multicolumn{2}{c}{ Change in disposable income (in pct.) } \\
Decile & Without WB & WB 2001 & WB 2006 & WB 2001 & WB 2006 \\
\hline & 333 & 325 & 299 & 0.050 & 0.238 \\
2 & 492 & 477 & 418 & 0.092 & 0.424 \\
3 & 901 & 879 & 781 & 0.102 & 0.538 \\
4 & 1297 & 1264 & 1140 & 0.122 & 0.567 \\
5 & 1374 & 1366 & 1240 & 0.034 & 0.449 \\
6 & 2131 & 2118 & 1980 & 0.044 & 0.457 \\
7 & 2693 & 2678 & 2562 & 0.045 & 0.352 \\
8 & 3650 & 3636 & 3520 & 0.033 & 0.287 \\
9 & 4689 & 4679 & 4591 & 0.022 & 0.184 \\
10 & 7093 & 7087 & 7049 & 0.009 & 0.061 \\
\hline \hline
\end{tabular}

Income deciles are constructed by equivalent household disposable income, using an equivalence scale of the squared root of household size. 
Tab. 2: Sample selection for labor supply model

\begin{tabular}{|c|c|c|c|c|c|c|c|c|}
\hline & \multicolumn{4}{|c|}{ Males } & \multicolumn{4}{|c|}{ Females } \\
\hline & $\begin{array}{r}\text { Unweightec } \\
\text { Number of cases }\end{array}$ & in $\%$ & $\begin{array}{c}\text { Weighted } \\
\text { Number of cases }\end{array}$ & in $\%$ & $\begin{array}{l}\text { Unweighted } \\
\text { Number of cases }\end{array}$ & in $\%$ & $\begin{array}{c}\text { Weighted } \\
\text { Number of cases }\end{array}$ & in $\%$ \\
\hline Population & 151806 & 100 & 4897974 & 100 & 153213 & 100 & 5137005 & 100 \\
\hline Adults & 106902 & 70 & 3845866 & 79 & 110215 & 72 & 4131619 & 80 \\
\hline In working age (18-65) & 83597 & 55 & 2814695 & 57 & 84011 & 55 & 2768708 & 54 \\
\hline With flexible labour supply & 59568 & 39 & 2032235 & 41 & 70003 & 46 & 2312637 & 45 \\
\hline - Couples ${ }^{1}$ & 32521 & 55 & 998253 & 49 & 32521 & 46 & 998253 & 43 \\
\hline - Single males & 14710 & 25 & 681730 & 34 & - & - & & \\
\hline - Single females & - & - & & & 13574 & 19 & 613322 & 27 \\
\hline - Males in couple ${ }^{2}$ & 3737 & 6 & 122049 & 6 & - & - & & \\
\hline - Females in couple ${ }^{3}$ & - & - & & & 11084 & 16 & 338450 & 15 \\
\hline - Other & 8549 & 14 & 228879 & 11 & 12815 & 18 & 362429 & 16 \\
\hline
\end{tabular}

${ }^{1}$ Both partners with a flexible labor supply.
${ }^{2}$ Male with a flexible labor supply living with a female partner with a fixed labor supply.
${ }^{3}$ Female with a flexible labor supply living with a male partner with a fixed labor supply. 
Tab. 5: Estimates: Model I

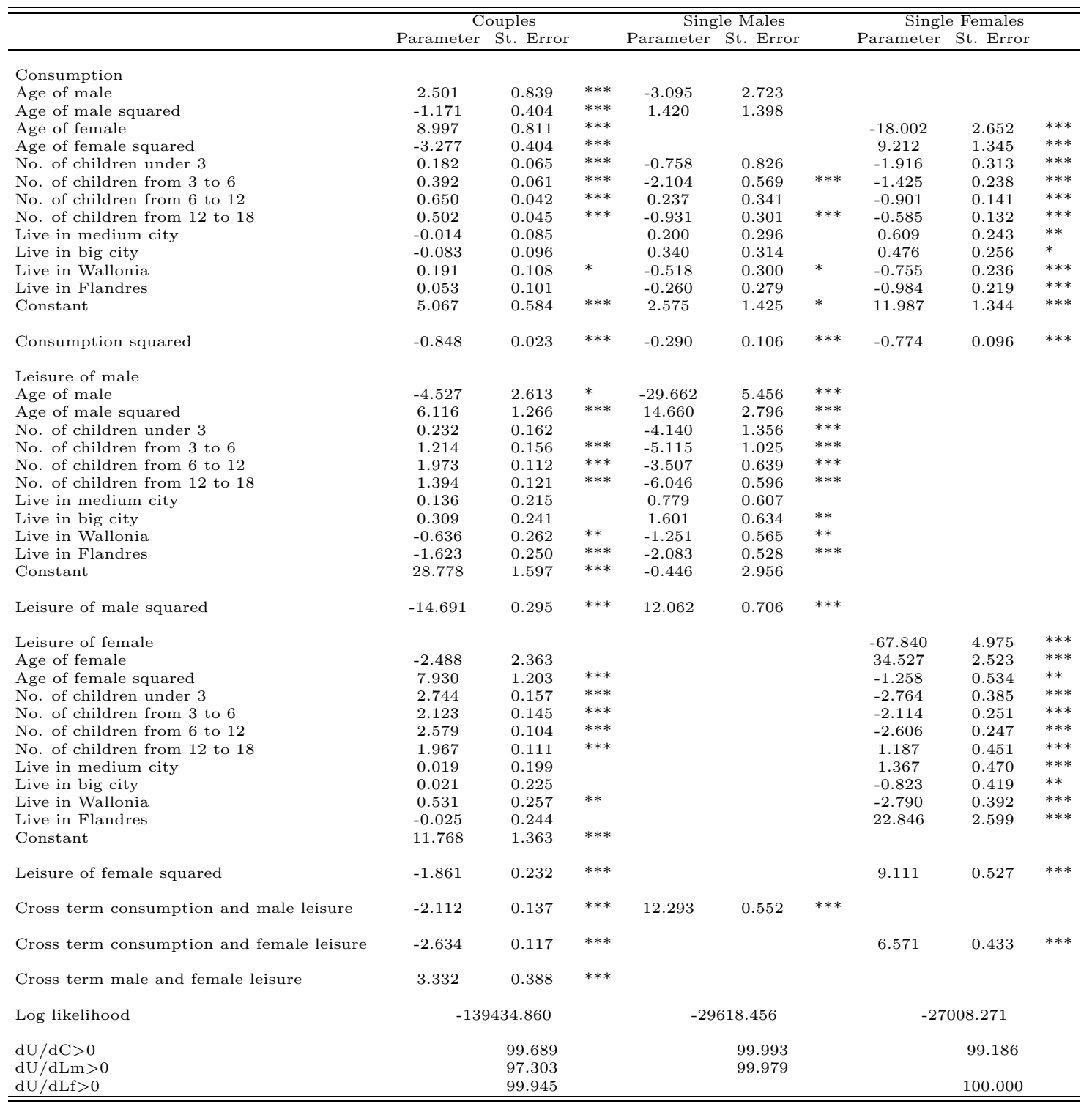


Tab. 6: Estimates: Model II

\begin{tabular}{|c|c|c|c|c|c|c|c|c|c|}
\hline \multirow{3}{*}{ Consumption } & \multicolumn{3}{|c|}{ Couples } & \multicolumn{3}{|c|}{$\begin{array}{l}\text { Single Males } \\
\end{array}$} & \multicolumn{3}{|c|}{$\begin{array}{l}\text { Single Females } \\
\end{array}$} \\
\hline & \multirow[t]{2}{*}{ Parameter } & \multicolumn{2}{|l|}{ St. Error } & \multicolumn{3}{|c|}{ Parameter St. Error } & \multicolumn{3}{|c|}{ Parameter St. Error } \\
\hline & & & & & & & & & \\
\hline Age of male & 2.150 & 0.834 & ** & -2.167 & 2.447 & & & & \\
\hline Age of male squared & -1.333 & 0.400 & $* * *$ & 1.237 & 1.252 & & & & \\
\hline Age of female & 10.259 & 0.800 & $* * *$ & & & & -7.029 & 2.501 & $* * *$ \\
\hline Age of female squared & -4.202 & 0.399 & $* * *$ & & & & 3.912 & 1.259 & $* * *$ \\
\hline No. of children under 3 & -0.137 & 0.059 & $* *$ & -0.010 & 0.821 & & -0.698 & 0.288 & ** \\
\hline No. of children from 3 to 6 & 0.082 & 0.057 & & -0.873 & 0.487 & * & -0.769 & 0.223 & $* * *$ \\
\hline No. of children from 6 to 12 & 0.318 & 0.040 & $* * *$ & 0.725 & 0.321 & ** & -0.557 & 0.130 & $* * *$ \\
\hline No. of children from 12 to 18 & 0.226 & 0.043 & $* * *$ & 0.014 & 0.280 & & -0.357 & 0.122 & *** \\
\hline Live in medium city & -0.003 & 0.084 & & 0.266 & 0.265 & & 0.551 & 0.229 & $* *$ \\
\hline Live in big city & -0.077 & 0.094 & & 0.482 & 0.284 & * & 0.455 & 0.242 & * \\
\hline Live in Wallonia & 0.276 & 0.101 & $* * *$ & -0.455 & 0.268 & * & -0.437 & 0.222 & ** \\
\hline Live in Flandres & 0.204 & 0.095 & ** & -0.480 & 0.252 & $*$ & -0.768 & 0.207 & *** \\
\hline Constant & 3.930 & 0.570 & $* * *$ & 3.841 & 1.319 & $* * *$ & 5.913 & 1.268 & $* * *$ \\
\hline Consumption squared & -0.650 & 0.022 & $* * *$ & -0.778 & 0.101 & $* * *$ & -0.604 & 0.086 & $* * *$ \\
\hline Leisure of male & & & & & & & & & \\
\hline Age of male & -5.912 & 2.357 & ** & -34.095 & 4.886 & $* * *$ & & & \\
\hline Age of male squared & 5.360 & 1.135 & $* * *$ & 17.007 & 2.488 & $* * *$ & & & \\
\hline No. of children under 3 & 0.288 & 0.141 & ** & -1.909 & 1.274 & & & & \\
\hline No. of children from 3 to 6 & 0.942 & 0.138 & $* * *$ & -2.220 & 0.880 & $* *$ & & & \\
\hline No. of children from 6 to 12 & 1.655 & 0.099 & $* * *$ & -1.238 & 0.579 & $* *$ & & & \\
\hline No. of children from 12 to 18 & 1.329 & 0.108 & $* * *$ & -2.860 & 0.538 & *** & & & \\
\hline Live in medium city & 0.213 & 0.193 & & 0.887 & 0.536 & * & & & \\
\hline Live in big city & 0.384 & 0.215 & * & 1.828 & 0.561 & $* * *$ & & & \\
\hline Live in Wallonia & -0.230 & 0.228 & & -0.953 & 0.493 & * & & & \\
\hline Live in Flandres & -1.214 & 0.218 & $* * *$ & -2.332 & 0.465 & $* * *$ & & & \\
\hline Constant & 33.523 & 1.905 & $* * *$ & 6.304 & 3.370 & * & & & \\
\hline Leisure of male squared & -15.976 & 0.952 & $* * *$ & 4.938 & 1.640 & $* * *$ & & & \\
\hline Leisure of female & & & & & & & -46.674 & 4.526 & *** \\
\hline Age of female & 2.391 & 2.191 & & & & & 24.297 & 2.272 & *** \\
\hline Age of female squared & 3.850 & 1.109 & $* * *$ & & & & 0.241 & 0.475 & \\
\hline No. of children under 3 & 2.160 & 0.141 & $* * *$ & & & & -1.122 & 0.350 & $* * *$ \\
\hline No. of children from 3 to 6 & 1.534 & 0.132 & $* * *$ & & & & -0.782 & 0.223 & $* * *$ \\
\hline No. of children from 6 to 12 & 1.911 & 0.095 & $* * *$ & & & & -1.153 & 0.223 & *** \\
\hline No. of children from 12 to 18 & 1.504 & 0.101 & $* * *$ & & & & 1.000 & 0.405 & $* *$ \\
\hline Live in medium city & 0.086 & 0.188 & & & & & 1.244 & 0.422 & $* * *$ \\
\hline Live in big city & 0.076 & 0.210 & & & & & -0.263 & 0.372 & \\
\hline Live in Wallonia & 0.675 & 0.228 & $* * *$ & & & & -2.303 & 0.351 & $* * *$ \\
\hline Live in Flandres & 0.240 & 0.218 & & & & & 30.534 & 3.185 & *** \\
\hline Constant & 39.186 & 1.887 & $* * *$ & & & & & & \\
\hline Leisure of female squared & -21.745 & 1.013 & $* * *$ & & & & -6.890 & 1.623 & $* * *$ \\
\hline Cross term consumption and male leisure & -3.558 & 0.140 & $* * *$ & 5.185 & 0.528 & $* * *$ & & & \\
\hline Cross term consumption and female leisure & -2.710 & 0.117 & $* * *$ & & & & 3.000 & 0.391 & $* * *$ \\
\hline Cross term male and female leisure & -5.391 & 0.386 & $* * *$ & & & & & & \\
\hline Males & & & & & & & & & \\
\hline Working 5 to 15 hours/week & 3.849 & 0.095 & $* * *$ & 3.554 & 0.147 & $* * *$ & & & \\
\hline Working 20 hours/week & 4.015 & 0.136 & $* * *$ & 3.536 & 0.203 & $* * *$ & & & \\
\hline Working 25 to 35 hours/week & 4.189 & 0.160 & $* * *$ & 3.786 & 0.234 & *** & & & \\
\hline Working 40 hours/week & 2.717 & 0.168 & $* * *$ & 2.493 & 0.237 & $* * *$ & & & \\
\hline Working 45 to 55 hours/week & 7.054 & 0.166 & $* * *$ & 7.156 & 0.230 & $* * *$ & & & \\
\hline Females & & & & & & & & & \\
\hline Working 5 to 15 hours/week & 3.841 & 0.077 & $* * *$ & & & & 3.732 & 0.130 & $* * *$ \\
\hline Working 20 hours/week & 2.609 & 0.113 & $* * *$ & & & & 2.969 & 0.188 & $* * *$ \\
\hline Working 25 to 35 hours/week & 3.139 & 0.127 & $* * *$ & & & & 3.705 & 0.217 & $* * *$ \\
\hline Working 40 hours/week & 1.210 & 0.131 & $* * *$ & & & & 1.615 & 0.227 & $* * *$ \\
\hline Working 45 to 55 hours/week & 5.277 & 0.158 & $* * *$ & & & & 5.899 & 0.251 & $* * *$ \\
\hline Log likelihood & \multicolumn{3}{|c|}{-95276.0090} & \multicolumn{3}{|c|}{-20181.2590} & \multicolumn{3}{|c|}{-18096.3240} \\
\hline $\mathrm{dU} / \mathrm{dC}>0$ & \multicolumn{3}{|c|}{99.6089} & \multicolumn{3}{|c|}{99.783} & & 98.790 & \\
\hline $\mathrm{dU} / \mathrm{dLm}>0$ & & 69.9461 & & & 95.218 & & & & \\
\hline $\mathrm{dU} / \mathrm{dLf}>0$ & & 59.1994 & & & & & & 71.904 & \\
\hline
\end{tabular}


Tab. 7: Estimates: Model III

\begin{tabular}{|c|c|c|c|c|c|c|c|c|c|}
\hline & & uples & & Sing & le Males & & Sing & e Females & \\
\hline & Parameter & St. Error & & Parameter & St. Error & & Parameter & St. Error & \\
\hline Consumption & & & & & & & & & \\
\hline Age of male & 3.837 & 0.884 & $* * *$ & -0.287 & 0.667 & & & & \\
\hline Age of male squared & -2.474 & 0.425 & $* * *$ & -0.015 & 0.086 & & & & \\
\hline Age of female & 8.758 & 0.801 & $* * *$ & & & & -1.064 & 0.694 & \\
\hline Age of female squared & -4.007 & 0.398 & $* * *$ & & & & 0.097 & 0.087 & \\
\hline No. of children under 3 & -0.357 & 0.062 & $* * *$ & 0.018 & 0.821 & & -1.002 & 0.290 & $* * *$ \\
\hline No. of children from 3 to 6 & -0.027 & 0.060 & & -1.197 & 0.502 & ** & -0.866 & 0.229 & $* * *$ \\
\hline No. of children from 6 to 12 & 0.180 & 0.042 & $* * *$ & 0.601 & 0.327 & * & -0.714 & 0.132 & $* * *$ \\
\hline No. of children from 12 to 18 & 0.065 & 0.044 & & -0.117 & 0.281 & & -0.475 & 0.124 & $* * *$ \\
\hline Live in medium city & 0.002 & 0.087 & & 0.270 & 0.266 & & 0.596 & 0.234 & $* *$ \\
\hline Live in big city & -0.032 & 0.098 & & 0.460 & 0.285 & & 0.362 & 0.246 & \\
\hline Live in Wallonia & 0.465 & 0.111 & $* * *$ & -0.422 & 0.294 & & 0.270 & 0.256 & \\
\hline Live in Flandres & 0.591 & 0.105 & $* * *$ & -0.179 & 0.281 & & 0.112 & 0.242 & \\
\hline Constant & -0.145 & 0.612 & & 0.841 & 1.400 & & 2.059 & 1.388 & \\
\hline Consumption squared & -0.434 & 0.026 & $* * *$ & -0.363 & 0.103 & $* * *$ & -0.309 & 0.087 & $* * *$ \\
\hline Leisure of male & & & & & & & & & \\
\hline Age of male & 2.954 & 3.565 & & -7.195 & 1.649 & $* * *$ & & & \\
\hline Age of male squared & -3.434 & 1.748 & ** & 0.674 & 0.219 & $* * *$ & & & \\
\hline No. of children under 3 & -0.514 & 0.150 & $* * *$ & -1.646 & 1.258 & & & & \\
\hline No. of children from 3 to 6 & 0.363 & 0.147 & ** & -2.598 & 0.891 & $* * *$ & & & \\
\hline No. of children from 6 to 12 & 0.944 & 0.105 & $* * *$ & -1.288 & 0.584 & ** & & & \\
\hline No. of children from 12 to 18 & 0.532 & 0.113 & $* * *$ & -2.758 & 0.534 & $* * *$ & & & \\
\hline Live in medium city & 0.195 & 0.203 & & 0.897 & 0.531 & * & & & \\
\hline Live in big city & 0.405 & 0.226 & * & 1.776 & 0.556 & $* * *$ & & & \\
\hline Live in Wallonia & 1.386 & 0.402 & $* * *$ & -1.109 & 0.716 & & & & \\
\hline Live in Flandres & 1.757 & 0.386 & $* * *$ & -1.564 & 0.691 & ** & & & \\
\hline Constant & 39.935 & 2.163 & $* * *$ & 33.447 & 3.526 & $* * *$ & & & \\
\hline Leisure of male squared & -26.220 & 0.573 & $* * *$ & -14.631 & 1.070 & $* * *$ & & & \\
\hline Leisure of female & & & & & & & & & \\
\hline Age of female & 15.434 & 3.104 & $* * *$ & & & & -6.916 & 1.537 & $* * *$ \\
\hline Age of female squared & -5.721 & 1.586 & $* * *$ & & & & 0.783 & 0.199 & *** \\
\hline No. of children under 3 & 1.739 & 0.148 & $* * *$ & & & & -0.363 & 0.483 & \\
\hline No. of children from 3 to 6 & 1.151 & 0.137 & $* * *$ & & & & -1.244 & 0.358 & $* * *$ \\
\hline No. of children from 6 to 12 & 1.405 & 0.098 & $* * *$ & & & & -1.081 & 0.228 & $* * *$ \\
\hline No. of children from 12 to 18 & 0.882 & 0.103 & $* * *$ & & & & -1.399 & 0.228 & $* * *$ \\
\hline Live in medium city & 0.077 & 0.192 & & & & & 1.089 & 0.414 & **** \\
\hline Live in big city & 0.085 & 0.215 & & & & & 1.077 & 0.431 & ** \\
\hline Live in Wallonia & 2.660 & 0.369 & $* * *$ & & & & 1.798 & 0.624 & $* * *$ \\
\hline Live in Flandres & 3.427 & 0.354 & $* * *$ & & & & 0.381 & 0.598 & \\
\hline Constant & 43.363 & 1.873 & $* * *$ & & & & 38.890 & 3.203 & $* * *$ \\
\hline Leisure of female squared & -36.989 & 0.623 & $* * *$ & & & & -20.644 & 0.978 & $* * *$ \\
\hline Cross term consumption and male leisure & -2.117 & 0.157 & $* * *$ & 6.263 & 0.539 & $* * *$ & & & \\
\hline Cross term consumption and female leisure & -1.115 & 0.130 & $* * *$ & & & & 3.964 & 0.407 & $* * *$ \\
\hline Cross term male and female leisure & 0.429 & 0.421 & & & & & & & \\
\hline Theta males & & & & & & & & & \\
\hline Wage & -0.213 & 0.007 & $* * *$ & -0.210 & 0.014 & $* * *$ & & & \\
\hline Age & -0.197 & 1.367 & & 0.171 & 0.427 & & & & \\
\hline Age squared & 1.662 & 0.669 & $* *$ & 0.056 & 0.059 & & & & \\
\hline Live in Wallonia & -0.554 & 0.146 & $* * *$ & 0.075 & 0.191 & & & & \\
\hline Live in Flandres & -1.148 & 0.141 & $* * *$ & -0.1492 & 0.187 & & & & \\
\hline Constant & 5.894 & 0.690 & $* * *$ & 5.544 & 0.744 & $* * *$ & & & \\
\hline Part time peak & 0.763 & 0.025 & $* * *$ & 0.824 & 0.037 & $* * *$ & & & \\
\hline Full time peak & 2.792 & 0.020 & $* * *$ & 2.780 & 0.034 & $* * *$ & & & \\
\hline Theta females & & & & & & & & & \\
\hline Wage & -0.328 & 0.006 & $* * *$ & & & & -0.388 & 0.012 & *** \\
\hline Age & -4.476 & 1.022 & $* * *$ & & & & -0.845 & 0.365 & $* *$ \\
\hline Age squared & 2.878 & 0.520 & $* * *$ & & & & 0.143 & 0.048 & $* * *$ \\
\hline Live in Wallonia & -0.832 & 0.123 & $* * *$ & & & & -0.677 & 0.176 & $* * *$ \\
\hline Live in Flandres & -1.238 & 0.118 & $* * *$ & & & & -0.778 & 0.172 & $* * *$ \\
\hline Constant & 10.833 & 0.502 & $* * *$ & & & & 9.956 & 0.679 & $* * *$ \\
\hline Part time peak & 0.600 & 0.0218 & $* * *$ & & & & 0.500 & 0.039 & $* * *$ \\
\hline Full time peak & 2.497 & 0.027 & $* * *$ & & & & 2.838 & 0.036 & $* * *$ \\
\hline Log likelihood & -93 & 18.7620 & & -20 & 81.9400 & & -17 & 433.8970 & \\
\hline $\mathrm{dU} / \mathrm{dC}>0$ & & 97.8199 & & & 99.3279 & & & 93.5180 & \\
\hline $\mathrm{dU} / \mathrm{dLm}>0$ & & 79.4704 & & & 79.7311 & & & & \\
\hline $\mathrm{dU} / \mathrm{dLf}>0$ & & 47.3965 & & & & & & 58.8710 & \\
\hline
\end{tabular}


Tab. 8: Estimates: Model IV

\begin{tabular}{|c|c|c|c|c|c|c|c|c|c|}
\hline \multirow{3}{*}{$\begin{array}{l} \\
\text { Consumption }\end{array}$} & \multicolumn{3}{|c|}{ Couples } & \multicolumn{3}{|c|}{ Single Males } & \multicolumn{3}{|c|}{ Single Females } \\
\hline & \multirow{2}{*}{$\begin{array}{c}\text { Parameter } \\
2.709\end{array}$} & \multicolumn{2}{|l|}{ St. Error } & \multirow{2}{*}{$\begin{array}{c}\text { Parameter } \\
1.847\end{array}$} & \multirow{2}{*}{$\begin{array}{c}\text { St. Error } \\
0.086\end{array}$} & \multicolumn{4}{|c|}{ Parameter St. Error } \\
\hline & & 0.039 & $* * *$ & & & $* * *$ & 0.994 & 0.064 & $* * *$ \\
\hline Exponent on Consumption & 0.668 & 0.013 & $* * *$ & 0.278 & 0.022 & $* * *$ & 0.082 & 0.032 & $* * *$ \\
\hline \multicolumn{10}{|l|}{ Leisure of male } \\
\hline Age of male & -5.242 & 0.692 & $* * *$ & -1.343 & 0.164 & $* * *$ & & & \\
\hline Age of male squared & 2.216 & 0.335 & $* * *$ & 0.154 & 0.021 & *** & & & \\
\hline No. of children under 3 & 0.067 & 0.028 & ** & -0.195 & 0.142 & & & & \\
\hline No. of children from 3 to 6 & 0.109 & 0.026 & $* * *$ & 0.197 & 0.128 & & & & \\
\hline No. of children from 6 to 12 & 0.117 & 0.018 & $* * *$ & -0.171 & 0.059 & $* * *$ & & & \\
\hline No. of children from 12 to 18 & 0.042 & 0.018 & $* *$ & -0.092 & 0.057 & & & & \\
\hline Live in medium city & 0.059 & 0.034 & * & 0.050 & 0.043 & & & & \\
\hline Live in big city & 0.169 & 0.039 & $* * *$ & 0.152 & 0.048 & $* * *$ & & & \\
\hline Live in Wallonia & 0.171 & 0.068 & ** & 0.056 & 0.070 & & & & \\
\hline Live in Flandres & 0.162 & 0.065 & ** & -0.101 & 0.067 & & & & \\
\hline Constant & 4.301 & 0.377 & $* * *$ & 3.730 & 0.389 & $* * *$ & & & \\
\hline Exponent on leisure of male & -1.474 & 0.065 & $* * *$ & -2.116 & 0.133 & $* * *$ & & & \\
\hline \multicolumn{10}{|l|}{ Leisure of female } \\
\hline Age of female & -0.985 & 0.213 & $* * *$ & & & & -0.588 & 0.103 & $* * *$ \\
\hline Age of female squared & 0.758 & 0.114 & $* * *$ & & & & 0.073 & 0.014 & $* * *$ \\
\hline No. of children under 3 & 0.280 & 0.016 & $* * *$ & & & & 0.380 & 0.059 & $* * *$ \\
\hline No. of children from 3 to 6 & 0.144 & 0.011 & $* * *$ & & & & 0.095 & 0.036 & $* * *$ \\
\hline No. of children from 6 to 12 & 0.137 & 0.009 & $* * *$ & & & & 0.163 & 0.024 & $* * *$ \\
\hline No. of children from 12 to 18 & 0.109 & 0.008 & $* * *$ & & & & 0.099 & 0.020 & $* * *$ \\
\hline Live in medium city & -0.006 & 0.012 & & & & & -0.001 & 0.030 & \\
\hline Live in big city & -0.005 & 0.014 & & & & & 0.034 & 0.032 & \\
\hline Live in Wallonia & 0.066 & 0.019 & $* * *$ & & & & 0.194 & 0.041 & $* * *$ \\
\hline Live in Flandres & 0.136 & 0.019 & $* * *$ & & & & 0.042 & 0.036 & \\
\hline Constant & 0.707 & 0.101 & $* * *$ & & & & 1.487 & 0.219 & $* * *$ \\
\hline Exponent on leisure of female & -3.722 & 0.072 & $* * *$ & & & & -2.938 & 0.146 & $* * *$ \\
\hline Cross term male and female leisure & 0.177 & 0.014 & $* * *$ & & & & & & \\
\hline \multicolumn{10}{|l|}{ Theta males } \\
\hline Wage & -0.199 & 0.007 & $* * *$ & -0.204 & 0.012 & *** & & & \\
\hline Age & -0.002 & 0.950 & & -2.037 & 0.287 & $* * *$ & & & \\
\hline Age squared & 1.382 & 0.458 & $* * *$ & 0.275 & 0.038 & $* * *$ & & & \\
\hline Live in Wallonia & -0.522 & 0.092 & $* * *$ & -0.139 & 0.126 & & & & \\
\hline Live in Flandres & -1.064 & 0.090 & $* * *$ & -0.525 & 0.123 & *** & & & \\
\hline Constant & 8.828 & 0.488 & $* * *$ & 9.257 & 0.542 & $* * *$ & & & \\
\hline Part time peak & 0.964 & 0.025 & $* * *$ & 0.852 & 0.038 & $* * *$ & & & \\
\hline Full time peak & 2.854 & 0.021 & $* * *$ & 2.664 & 0.035 & $* * *$ & & & \\
\hline \multicolumn{10}{|l|}{ Theta females } \\
\hline Wage & -0.305 & 0.006 & $* * *$ & & & & -0.375 & 0.012 & $* * *$ \\
\hline Age & -3.387 & 0.625 & $* * *$ & & & & -3.020 & 0.256 & $* * *$ \\
\hline Age squared & 2.439 & 0.318 & $* * *$ & & & & 0.394 & 0.033 & $* * *$ \\
\hline Live in Wallonia & -0.318 & 0.067 & $* * *$ & & & & -0.345 & 0.102 & $* * *$ \\
\hline Live in Flandres & -0.695 & 0.065 & $* * *$ & & & & -0.709 & 0.099 & $* * *$ \\
\hline Constant & 7.264 & 0.304 & $* * *$ & & & & 12.458 & 0.501 & $* * *$ \\
\hline Part time peak & 0.894 & 0.021 & $* * *$ & & & & 0.635 & 0.039 & $* * *$ \\
\hline Full time peak & 2.203 & 0.024 & $* * *$ & & & & 2.655 & 0.033 & $* * *$ \\
\hline Log likelihood & \multicolumn{3}{|c|}{-95057.5150} & \multicolumn{2}{|c|}{-19995.1430} & & \multicolumn{3}{|c|}{-17468.2260} \\
\hline $\mathrm{dU} / \mathrm{dC}>0$ & \multirow{2}{*}{\multicolumn{3}{|c|}{100.00}} & \multicolumn{3}{|c|}{100.00} & & 100.00 & \\
\hline $\mathrm{dU} / \mathrm{dLm}>0$ & & & & & 100.00 & & & & \\
\hline $\mathrm{dU} / \mathrm{dLf}>0$ & & 100.00 & & & & & & 100.00 & \\
\hline
\end{tabular}

Tab. 9: Labour supply elasticities

\begin{tabular}{|c|c|c|c|c|c|}
\hline & \multicolumn{2}{|c|}{ Singles } & \multicolumn{2}{|c|}{ Couples } \\
\hline & & Females & Males & Females & Males \\
\hline \multirow[t]{2}{*}{ Model I } & Hours & 0.439 & 0.418 & 0.916 & 0.453 \\
\hline & Participation & 0.262 & 0.281 & 0.32 & 0.124 \\
\hline \multirow[t]{2}{*}{ Model II } & Hours & 0.414 & 0.398 & 0.763 & 0.439 \\
\hline & Participation & 0.404 & 0.400 & 0.592 & 0.342 \\
\hline \multirow[t]{2}{*}{ Model III } & Hours & 0.077 & 0.167 & 0.311 & 0.218 \\
\hline & Participation & 0.114 & 0.214 & 0.236 & 0.168 \\
\hline \multirow[t]{2}{*}{ Model IV } & Hours & 0.117 & 0.213 & 0.462 & 0.286 \\
\hline & Participation & 0.121 & 0.203 & 0.312 & 0.204 \\
\hline
\end{tabular}


Tab. 10: Expected effects of the Workbonus on labour supply (figures in 1000s)

\begin{tabular}{|c|c|c|c|c|c|c|c|c|c|c|}
\hline & \multicolumn{4}{|c|}{ Hours } & \multicolumn{4}{|c|}{ Participation } & \multirow{3}{*}{$\begin{array}{c}\text { Hours } \\
\text { Total }\end{array}$} & \multirow{3}{*}{$\begin{array}{c}\text { Participation } \\
\text { Total }\end{array}$} \\
\hline & \multicolumn{2}{|c|}{ Singles } & \multicolumn{2}{|c|}{ Couples } & \multicolumn{2}{|c|}{ Singles } & \multicolumn{2}{|c|}{ Couples } & & \\
\hline & Females & Males & Females & Males & Females & Males & Females & Males & & \\
\hline \multicolumn{11}{|c|}{ No Workbonus } \\
\hline Model II & -3 & -2 & -6 & -4 & -3 & -2 & -7 & -4 & -15 & -17 \\
\hline Model IV & -1 & -1 & -3 & -2 & -1 & -1 & -4 & -2 & -7 & -8 \\
\hline \multicolumn{11}{|c|}{ Workbonus 2006} \\
\hline Model II & 4 & 4 & 9 & 6 & 4 & 4 & 11 & 6 & 23 & 25 \\
\hline Model IV & 1 & 2 & 5 & 3 & 2 & 2 & 6 & 3 & 12 & 13 \\
\hline \multicolumn{11}{|c|}{ Extended Workbonus } \\
\hline Model II & 8 & 10 & 22 & 19 & 9 & 12 & 24 & 18 & 59 & 62 \\
\hline Model IV & 2 & 5 & 11 & 11 & 3 & 6 & 11 & 10 & 29 & 30 \\
\hline
\end{tabular}

Tab. 11: Reduction on SSC revenue and budgetary cost (Million EUR)

\begin{tabular}{lc}
\hline \hline & Total budgetary cost \\
\hline & \\
Official statistics ${ }^{1}$ & 481 \\
Static microsimulation & 443 \\
Model II - after behavioural adjustment & 524 \\
Model IV - after behavioural adjustment & 483 \\
\hline \hline 1 Total spending on the measure in 2006 minus total spending \\
in 2001 (expressed in 2006 values). Source: ONSS/RSZ.
\end{tabular}

Tab. 12: Cost per participant and FTE unit (EUR/Year)

\begin{tabular}{lcc}
\hline \hline & 2001 Workbonus & 2006 Workbonus \\
\hline Cost per additional participant (model II) & 11430 & 21015 \\
Cost per additional participant (model IV) & 18404 & 40330 \\
Cost per additional FTE position (model II) & 12811 & 21284 \\
Cost per additional FTE position (model IV) & 20807 & 41743 \\
\hline \hline
\end{tabular}


Fig. 1: Subsidy on low skilled's social security contributions

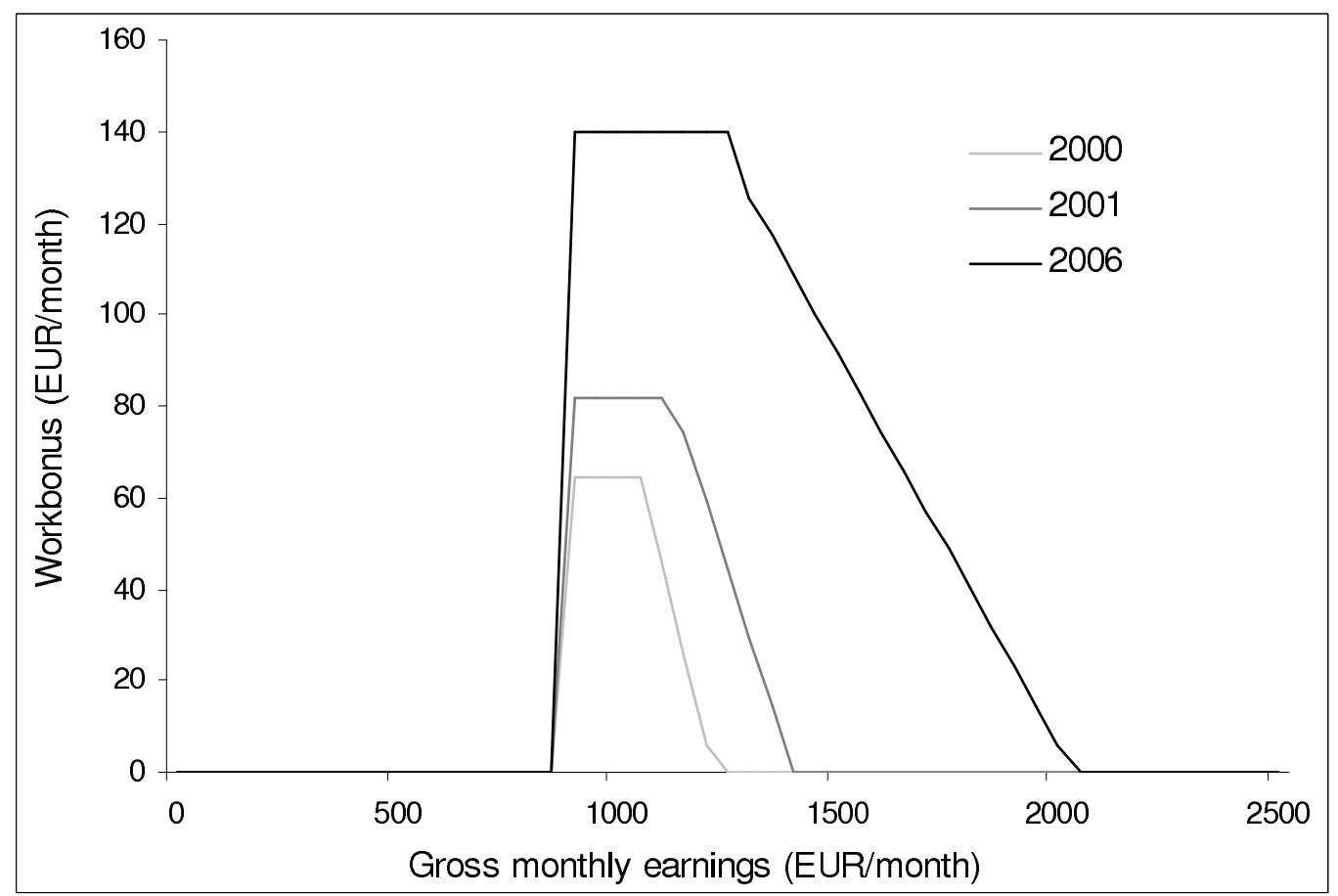

Amounts are in EUR/month. 
Fig. 2: Sample selection and modeling strategy

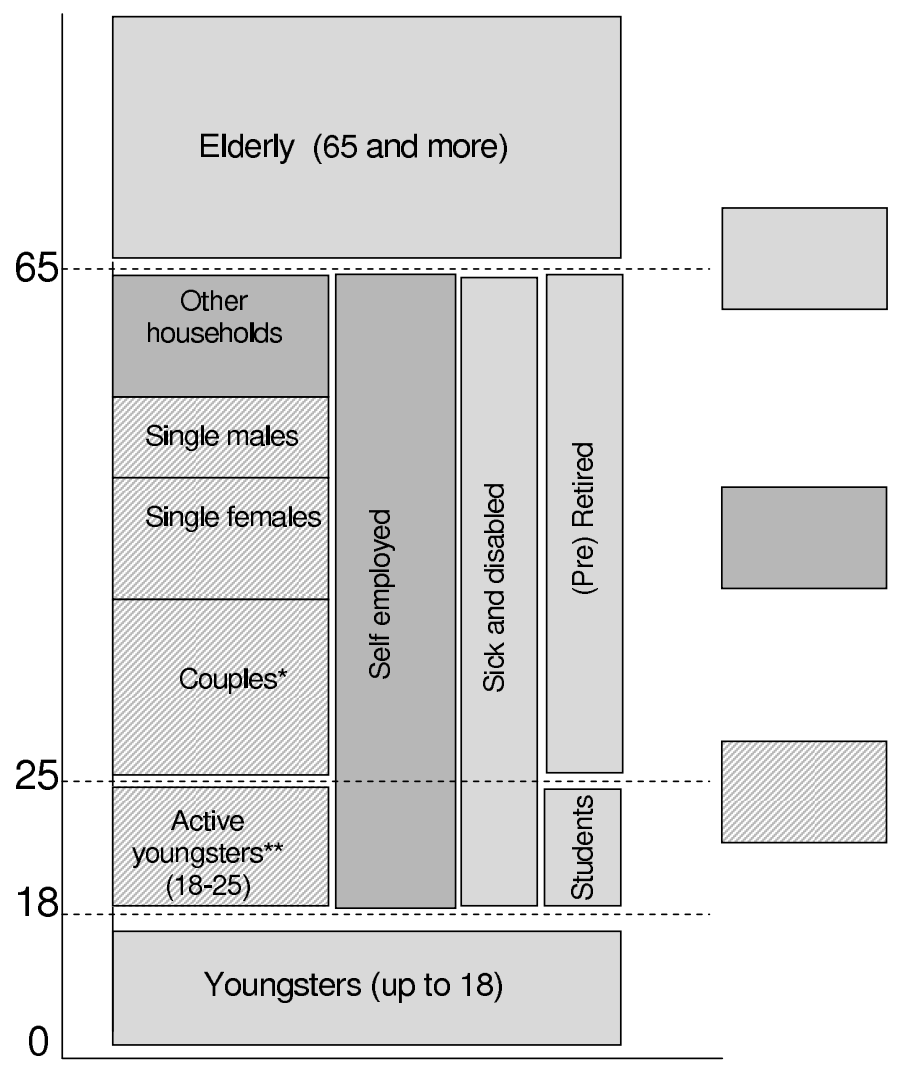

Population not available for the labour market: youngsters (up to 18), students (18 to 25), pre-retired, sick and disabled and elderly population

Population available for the labour market, labour supply not modeled: individuals living in non couple and non single households, self employed

Population available for the labour market, labour supply modeled: employees, unemployed and inactive individuals living in single adult households or in couple

*both partners available for the labour market

$* *$ only youngsters living as singles or in couple. 
Fig. 3: Observed and predicted frequencies (Males in couples)

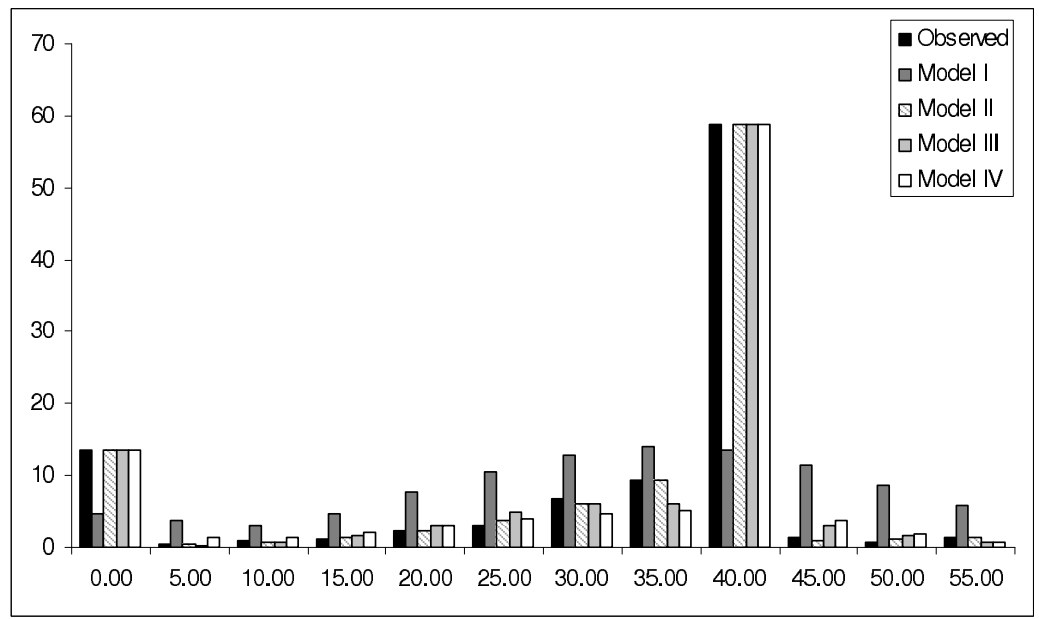

Fig. 4: Observed and predicted frequencies (Females in couples)

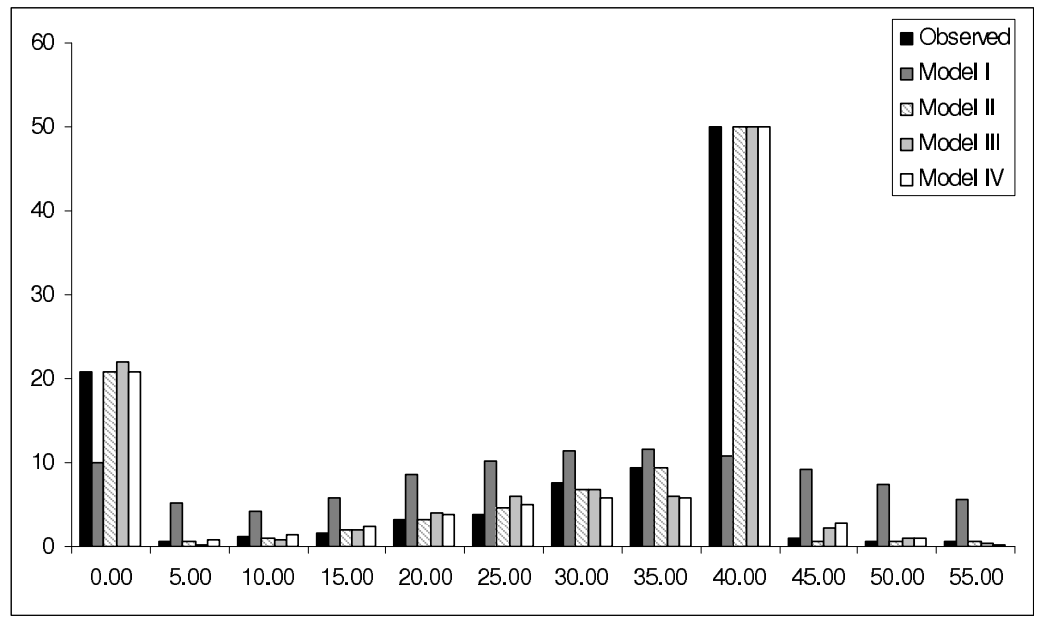


Fig. 5: Observed and predicted frequencies (Single males)

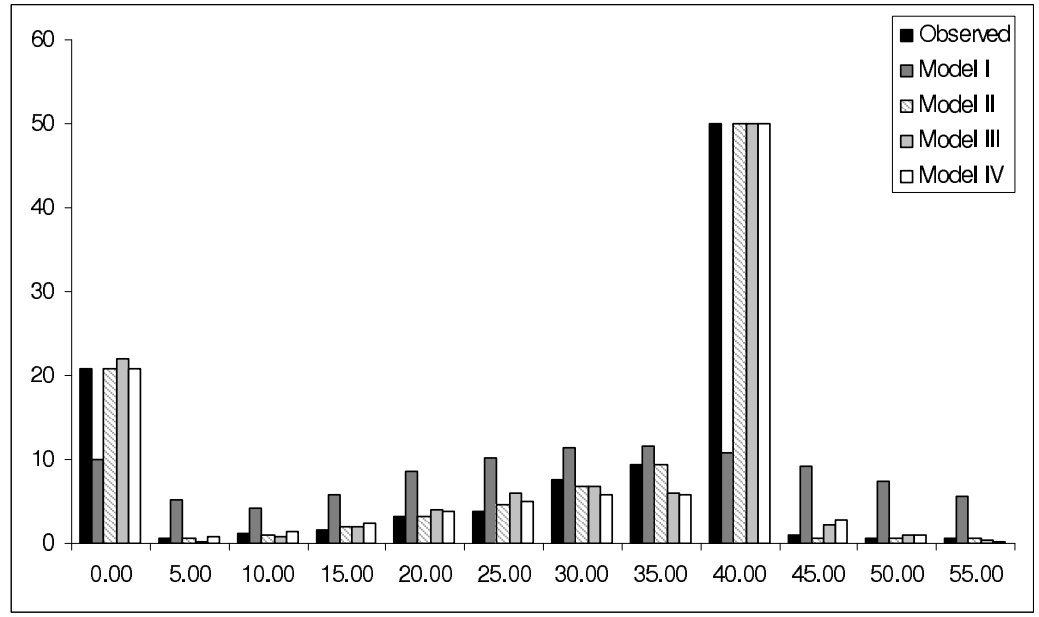

Fig. 6: Observed and predicted frequencies (Single females)

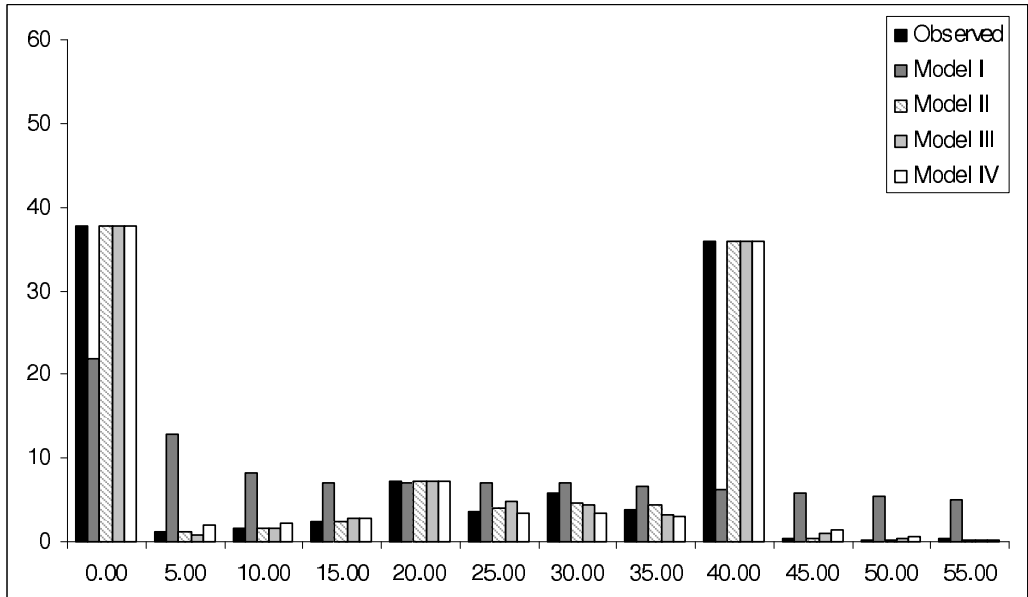


Fig. 7: Predicted change in labour supply by equivalent income deciles

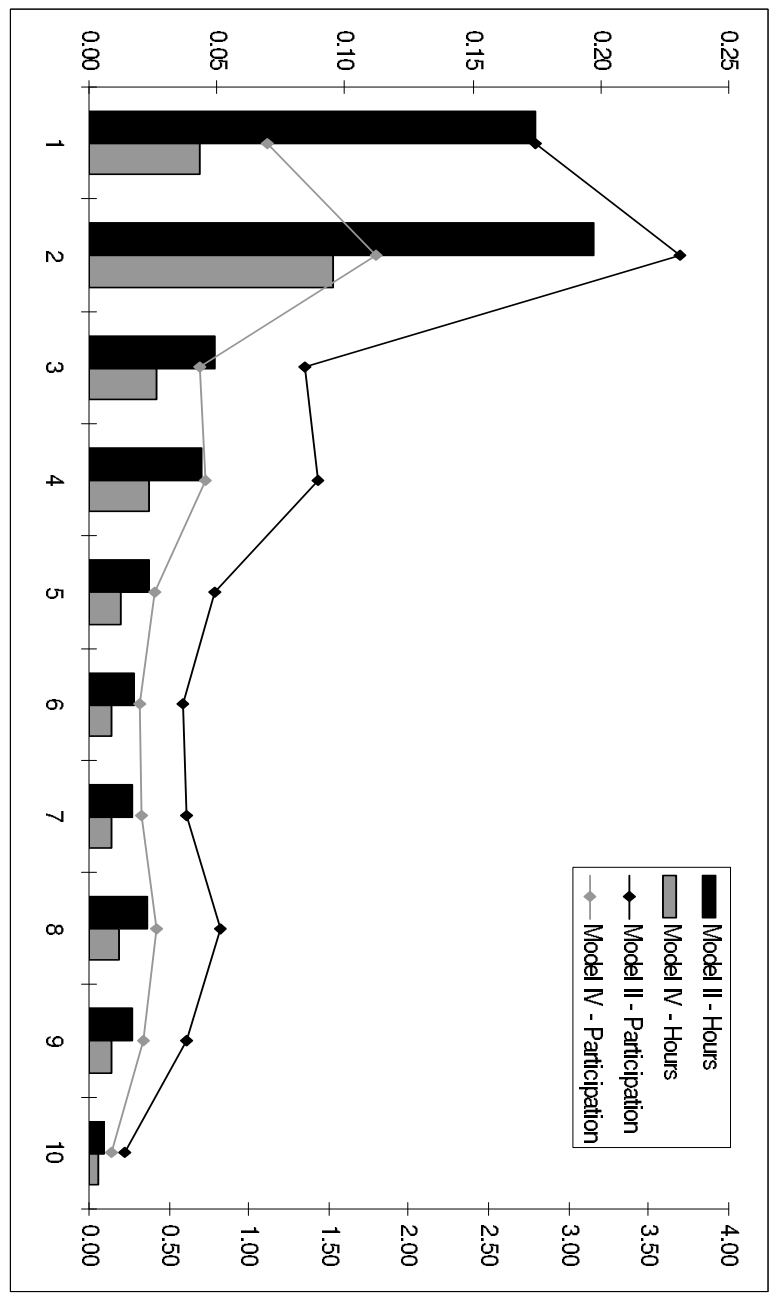




\section{References}

Aaberge, R., U. Colombino, and S. Strøm (2004): "Do More Equal Slices Shrink the Cake? An Empirical Investigation of Tax-Transfer Reform Proposals in Italy," Journal of Population Economics, 17, 767-785.

Aaberge, R., U. Colombino, and T. Wennemo (2006): "Evaluating Alternative Representations of the Choice Sets in Models of Labour Supply," IZA Discussion Paper, No. 1985.

Bargain, O., M. Caliendo, P. HaAn, and K. Orsini (2005): “Making Work Pay' in a Rationed Labour Market: the Mini-Job Reform in Germany," DIW Working Paper, No. 536.

Bargain, O., and K. Orsini (2006): "In-Work Policies in Europe: Killing Two Birds with One Stone," Labour Economics, pp. 667-698.

Bingley, P., And I. Walker (1997): "The Labour Supply, Unemployment and Participation of Lone Mothers in In-Work Transfer Programmes," Economic Journal, 107, 1375-1390.

Bloemen, H. (2008): "Job Search, Hours Restrictions, and Desired Hours of Work," Journal of Labor Economics, 26, 137-179.

Bloemen, H., And A. KAPteyn (2008): "The estimation of utility consistent labor supply models by means of simulated scores," Journal of Applied Econometrics, 23(4), 395-422.

Blundell, R., A. Duncan, J. McCrae, and C. Meghir (2000): "The Labour Market impact of the Working Families Tax Credit," Fiscal Studies, 21, 75-104.

Blundell, R., And T. MaCurdy (1999): "Labor Supply: A Review of Alternative Approaches," in Handbook of Labor Economics, Vol. 3A, ed. by O. Ashenfelter, and D. Card, pp. 1559-1695. Elsevier, Amsterdam, North Holland.

Bonin, H., W. Kempe, and H. Schneider (2002): "Household labor supply effects of low-wage subsidies in Germany," IZA Discussion Paper, No. 637.

DagsviK, J., And Z. JiA (2008): "An Alternative Approach to Labor Supply Modelling, Emphasizing Job-type as Choice Variable.," Mimeo.

Dagsvik, J., And S. Strøm (1989): "A Labour Supply Model for Married Couples with Nonconvex Budget Sets and Latent Rationing," Central bureau of statistics. discussion paper.

Dagsvik, J., and S. Strøm (2006): "Sectoral Labour Supply, Choice Restrictions and Functional Form," Journal of Applied Econometrics, 21, 803-826.

Duncan, A., and C. Giles (1996): "Labour Supply Incentives and Recent Family Credit Reforms," The Economic journal, 106, 142-55.

Eissa, N., And H. Hoynes (2004): "Taxes and the Labor Market Participation of Married Couples: The Earned Income Tax Credit," Journal of Public Economics, 88, 1931-1958.

Eissa, N., And J. Liebman (1996): "Labor Supply Response to the Earned Income Tax Credit," Quarterly Journal of Economics, 111, 605-37.

HaAn, P. (2006): "Much ado about nothing: Conditional Logit vs. Random Coefficient Models for Estimating Labour Supply Elasticities," Applied Economics Letters, 13(4), 251 - 256.

Haan, P., And V. Steiner (2005): "Distributional Effects of the German Tax Reform 2000 - A Behavioral Microsimulation Analysis," Schmollers Jahrbuch - Journal of Applied Social Science Studies, 125, 39-49. 
Hausman, J. A., And P. Ruud (1984): "Family Labor Supply with Taxes," American Economic Review, 74, 242-253.

McFadden, D. (1974): "Conditional Logit Analysis of Qualitative Choice Behavior," in Frontiers in Econometrics, ed. by P. Zarembka. Academic Press, New York.

Moore, M. P., And P. Ranjan (2005): "Globalisation VS Skill Biased Technological Change: Implications for Unemployment and Wage Inequality," Economic Journal, 115, 391-422.

Orsini, K. (2006a): "Is Belgium 'Making Work Pay?'," Ces Discussion Paper, no. 06-05.

(2006b): "Tax and Benefit Reforms and the Labour Market: What can we Learn?," Ces Discussion Paper, no. 06-06.

VAn Soest, A. (1995): "Structural Models of Family Labor Supply: A Discrete Choice Approach," Journal of Human Resources, 30, 63-88.

Van Soest, A., M. Das, and X. Gong (2002): "A Structural Labour Supply Model with Flexible Preferences," Journal of Econometrics, 107, 345-374.

Vermandere, C., And E. Stevens (2002): "Een volgende aflevering in het datawarehousefeuilleton...," Over.werk no. 1-2/2002. 